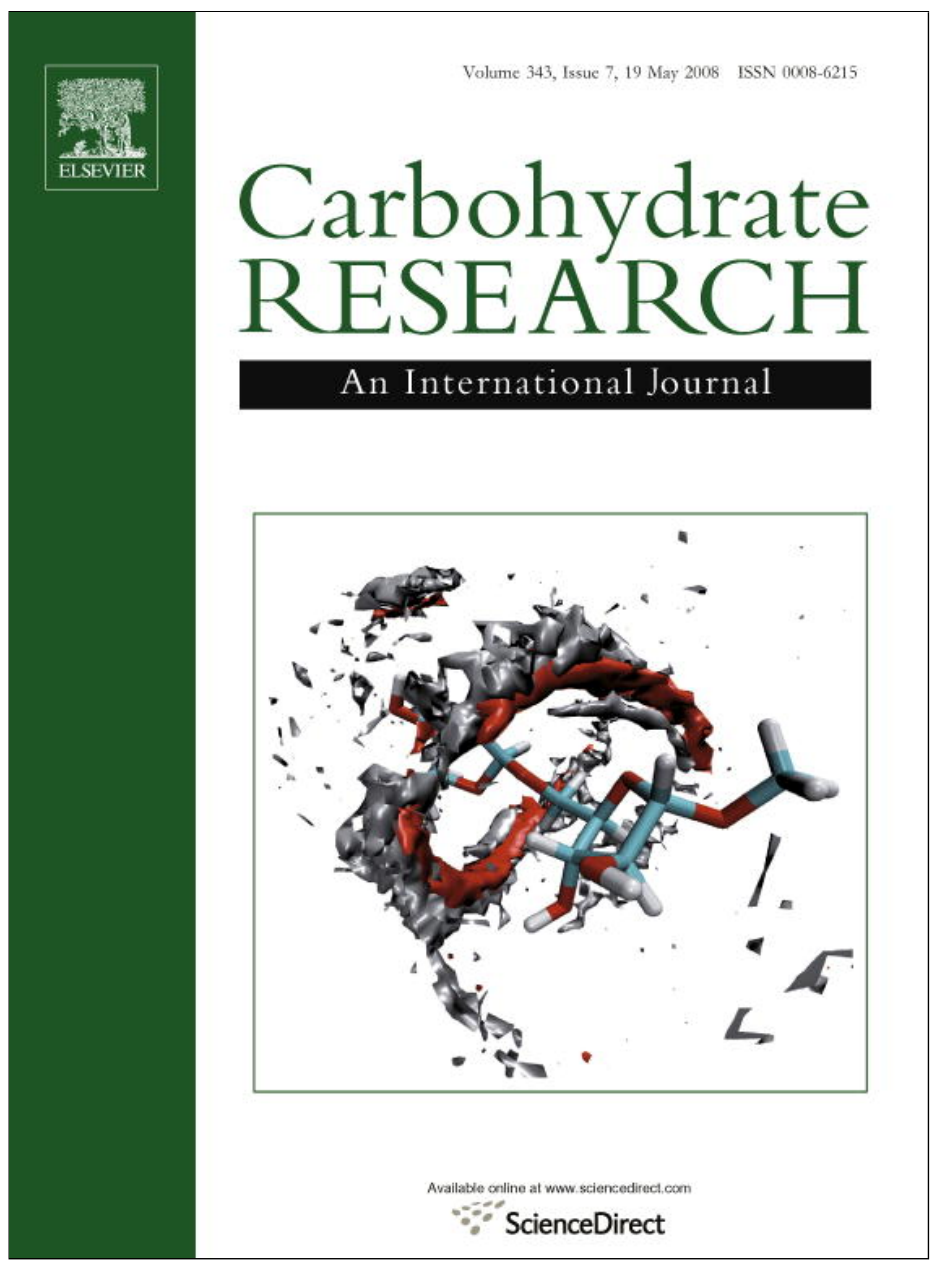

This article appeared in a journal published by Elsevier. The attached copy is furnished to the author for internal non-commercial research and education use, including for instruction at the authors institution and sharing with colleagues.

Other uses, including reproduction and distribution, or selling or licensing copies, or posting to personal, institutional or third party websites are prohibited.

In most cases authors are permitted to post their version of the article (e.g. in Word or Tex form) to their personal website or institutional repository. Authors requiring further information regarding Elsevier's archiving and manuscript policies are encouraged to visit:

http://www.elsevier.com/copyright 


\title{
Structural analysis of the $\alpha$-D-glucan (EPS35-5) produced by the Lactobacillus reuteri strain 35-5 glucansucrase GTFA enzyme
}

\author{
Sander S. van Leeuwen, ${ }^{\text {a }}$ Slavko Kralj, ${ }^{\text {,c }}$ Ineke H. van Geel-Schutten, ${ }^{c, \dagger}$ Gerrit J. Gerwig, ${ }^{\text {a }}$ \\ Lubbert Dijkhuizen $^{\mathrm{b}, \mathrm{c}}$ and Johannis P. Kamerling ${ }^{\mathrm{a}, *}$ \\ ${ }^{a}$ Bijvoet Center, Department of Bio-Organic Chemistry, Utrecht University, Padualaan 8, 3584 CH Utrecht, The Netherlands \\ ${ }^{\mathrm{b}}$ Department of Microbiology, Groningen Biomolecular Sciences and Biotechnology Institute, University of Groningen, \\ Kerklaan 30, 9751 NN Haren, The Netherlands \\ ${ }^{\mathrm{c}}$ Centre for Carbohydrate Bioprocessing, TNO_University of Groningen, Kerklaan 30, 9751 NN Haren, The Netherlands
}

Received 2 November 2007; received in revised form 15 January 2008; accepted 30 January 2008

Available online 7 February 2008

\begin{abstract}
The neutral exopolysaccharide EPS35-5 (reuteran) produced from sucrose by the glucansucrase GTFA enzyme from Lactobacillus reuteri $35-5$ was found to be a $(1 \rightarrow 4,1 \rightarrow 6)-\alpha$-D-glucan, with no repeating units present. Based on linkage analysis and $1 \mathrm{D} / 2 \mathrm{D}{ }^{1} \mathrm{H}$ and ${ }^{13} \mathrm{C}$ NMR spectroscopy of intact EPS35-5, as well as MS and NMR analysis of oligosaccharides obtained by partial acid hydrolysis and enzymatic hydrolysis, using pullulanase M1 (Klebsiella planticola), of EPS35-5, a composite model, that includes all identified structural elements, was formulated as follows:
\end{abstract}

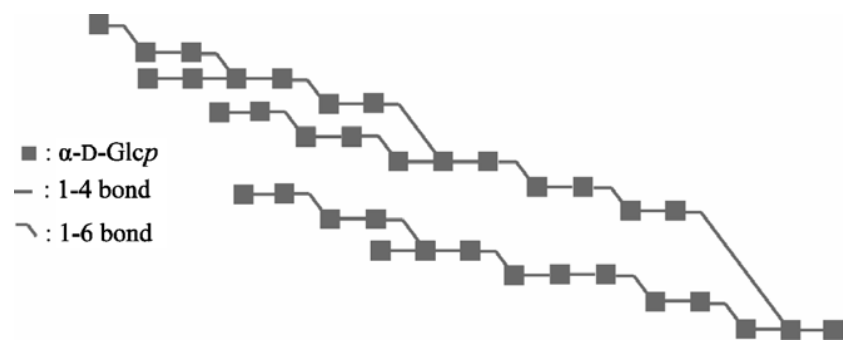

(C) 2008 Elsevier Ltd. All rights reserved.

Keywords: $\alpha$-D-Glucan; Polysaccharide structural analysis; GTFA Glucansucrase; Lactobacillus reuteri $35-5$; Reuteran; ${ }^{1} \mathrm{H}$ NMR spectroscopy

\section{Introduction}

The use of lactic acid bacteria (LAB) in food production is commonplace, due to their status as generally recognised as safe (GRAS). One of the reasons for the use of LAB in food (especially dairy) is the generation of large

\footnotetext{
*Corresponding author. Tel.: +31 30253 3479; fax: +31 30254 0980; e-mail: j.p.kamerling@uu.nl

${ }^{\dagger}$ Present address: Materials Innovation Centre B.V., Julianalaan 136, 2628 BL Delft, The Netherlands.
}

exopolysaccharides (EPSs) in the food medium. The physico-chemical properties of the EPSs lie at the basis of their clearly defined functions in food as stabilisers, gelling agents and thickeners. ${ }^{1}$ Whereas in vivo the function of these EPSs is not completely clear, they seem to be involved in adhesion, ${ }^{2}$ certain cellular processes ${ }^{3}$ and protection against dehydration, phagocytosis or toxins. ${ }^{3}$

Until recently, EPSs from LAB that were analysed were generally heteropolysaccharides with repeatingunit structures. ${ }^{4}$ Structures of LAB homopolysaccharides produced by specific glucansucrase enzymes have not been extensively analysed. Only initial structural 
studies have been performed on dextrans (polysaccharides containing mostly $(\alpha 1 \rightarrow 6)$ linkages) with $(\alpha 1 \rightarrow 2)$, $(\alpha 1 \rightarrow 3)$ and $(\alpha 1 \rightarrow 4)$ branches, ${ }^{5,6}$ or linear homopolysaccharides. ${ }^{7}$ Recently, a structural-reporter-group concept for $\alpha$-glucans was established, ${ }^{8}$ and applied to the analysis of an $\alpha$-glucan produced by the glucansucrase GTF180 enzyme, resulting in a detailed composite model..$^{9}$

Previous studies of GTFA, a glucansucrase enzyme with large similarity to GTF180, revealed that it produces EPS35-5 (reuteran), an $\alpha$-glucan with $(\alpha 1 \rightarrow 4)$ and $(\alpha 1 \rightarrow 6)$ glycosidic linkages. ${ }^{10}$ Here, we describe the structural analysis of this homopolysaccharide, using the structural-reporter groups established previously, ${ }^{8}$ and enhanced by application on EPS180. ${ }^{9}$ The various data were combined to formulate a composite model, that includes all structural features identified in EPS35-5.

\section{Results}

\subsection{Composition of EPS35-5}

Monosaccharide analysis of EPS35-5 revealed the presence of glucose only and a carbohydrate content of $100 \%$ (w/w). Methylation analysis of EPS35-5 showed the presence of terminal, 4-substituted, 6-substituted and 4,6-disubstituted glucopyranose in a molar percentage of $14 \%, 46 \%, 26 \%$ and $14 \%$. $1 \mathrm{D}{ }^{1} \mathrm{H}$ NMR spectroscopy (Fig. 1) showed an $\alpha$-anomeric configuration for all glucose residues. Of these residues, $58 \%$ is involved in $(\alpha 1 \rightarrow 4)$ linkages $\left(\delta_{\mathrm{H}-1} \sim 5.36\right.$ and $\left.\sim 5.33\right)$ and $42 \%$ in $(\alpha 1 \rightarrow 6)$ linkages $\left(\delta_{\mathrm{H}-1} \sim 4.96\right)$, which is in agreement with the linkage ratios found by methylation analysis (see also Ref. 10). The $(\alpha 1 \rightarrow 4)$ anomeric ${ }^{1} \mathrm{H}$ signal is split into two overlapping broad peaks, indicating that $(-) \alpha-D-G l c p-(1 \rightarrow 4)-*$ residues in EPS35-5 exist in at least two significantly different structural elements. The $(\alpha 1 \rightarrow 6)$ anomeric ${ }^{1} \mathrm{H}$ signal is represented by a single peak, which may reflect a more uniform structural element for the $(-) \alpha$-D-Glcp-( $1 \rightarrow 6)$ - residues.

\subsection{Partial acid hydrolysis}

After the evaluation of various partial acid hydrolysis conditions, making use of MALDI-TOF-MS and 1D ${ }^{1} \mathrm{H}$ NMR spectroscopy, a large batch of EPS35-5 $(500 \mathrm{mg})$ was subjected to partial acid hydrolysis with

\footnotetext{
${ }^{\ddagger}$ For Glc residues at semi-defined places in the structure (-) $\alpha$-D-Glc $p$ $(1 \rightarrow x)$ - or $-(1 \rightarrow x)-\alpha-D-G l c p(-)$ is used. When the structural context of the residue is precisely known, this is indicated as follows: $-(1 \rightarrow x)-\alpha-$ D-Glcp-( $1 \rightarrow y)$ - describing an $x$-substituted residue with an $(1 \rightarrow y)$ linkage. In the case of a non-reducing terminal residue $\alpha$-D-Glcp$(1 \rightarrow x)$ - is used, a reducing terminal residue is indicated with $-(1 \rightarrow x)$ D-Glcp.
}

$0.5 \mathrm{M}$ TFA $\left(2 \mathrm{~h}, 90^{\circ} \mathrm{C}\right)$. The latter conditions rendered a pool of oligosaccharides in a broad distribution of degrees of polymerisation, as indicated by MALDITOF-MS (data not shown), 1D ${ }^{1} \mathrm{H}$ NMR spectroscopy (data not shown) and HPAEC analysis on CarboPac PA-100 (Fig. 2A). The glycan pool was pre-fractionated on Bio-Gel P-4, yielding four subpools, denoted by I-IV. The fragment size distribution in each subpool was determined by MALDI-TOF-MS (data not shown). Subpool I consisted of fragments smaller than three Glc units. Subpool II contained fragments of three up to five Glc residues. Subpool III consisted of fragments of five up to seven Glc units. Finally, subpool IV consisted of fragments of seven residues and larger. The fragments in subpool IV were mainly too large for full structural analysis, and were not studied further. Subpools I-III were subfractionated by HPAEC on CarboPac PA-1, using a $0-300 \mathrm{mM} \mathrm{NaOAc}$ gradient in $100 \mathrm{mM} \mathrm{NaOH}$ (Fig. 2B), and fractions $\mathbf{1}$ and $\mathbf{2}$ were isolated from subpool I, fractions 3-5 from subpool II and fractions 6 and 7 from subpool III.

2.2.1. Fraction 1. Profiling of fraction 1 on CarboPac PA-100 showed one peak. The 1D ${ }^{1} \mathrm{H}$ NMR spectrum of fraction 1 corresponded with that of isomaltose, $\alpha-$ D-Glc $p$-(1 $\rightarrow 6)$-D-Glc $p$ (Scheme 1). ${ }^{8}$

2.2.2. Fraction 2. Analysis on CarboPac PA-100 revealed that fraction 2 consisted of one compound. The 1D ${ }^{1} \mathrm{H}$ NMR spectrum corresponded with that of maltose, $\alpha$-D-Glc $p$-(1 $\rightarrow 4)$-D-Glc $p$ (Scheme 1$){ }^{8}$

2.2.3. Fraction 3. Analysis of fraction 3 on CarboPac PA-100 showed two component peaks. Fraction 3 was further separated on CarboPac PA-1, isocratically eluted with $100 \mathrm{mM} \mathrm{NaOAc}$ in $100 \mathrm{mM} \mathrm{NaOH}$ (Fig. 2C), yielding one major fraction 3a. The MALDI-TOF mass spectrum of fraction 3a revealed an $[\mathrm{M}+\mathrm{Na}]^{+}$pseudomolecular ion at $\mathrm{m} / \mathrm{z}$ 527, corresponding with $\mathrm{Hex}_{3}$. The $1 \mathrm{D}{ }^{1} \mathrm{H}$ NMR spectrum of $\mathbf{3 a}$ (Fig. 3A) showed five anomeric signals at $\delta 5.412$ (D $\left.\mathrm{H}-1,{ }^{3} J_{1,2} 3.7 \mathrm{~Hz}\right), 5.240\left(\mathbf{R} \alpha \mathrm{H}-1,{ }^{3} J_{1,2} 3.8 \mathrm{~Hz}\right), 4.958$ $\left(\mathbf{B}_{\beta} \mathrm{H}-1,{ }^{3} J_{1,2} 3.8 \mathrm{~Hz}\right), 4.950\left(\mathbf{B}_{\alpha} \mathrm{H}-1,{ }^{3} J_{1,2} 3.8 \mathrm{~Hz}\right)$ and $4.669\left(\mathbf{R} \beta \mathrm{H}-1,{ }^{3} J_{1,2} 8.1 \mathrm{~Hz}\right)$. Starting from the anomeric signals in the $2 \mathrm{D}^{1} \mathrm{H}-{ }^{1} \mathrm{H}$ TOCSY spectrum (not shown), all non-anomeric signals could be assigned (Table 1). The $\mathbf{R} \boldsymbol{\alpha}$ and $\mathbf{R} \boldsymbol{\beta} \mathrm{H}-1$ values correspond with those found

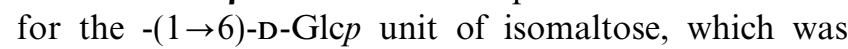
established as a structural-reporter-group signal for this type of unit. ${ }^{8}$ This was further confirmed by the $\mathbf{R}$ H-5 ( $\delta 4.00$ for $\mathbf{R} \boldsymbol{\alpha}$ and $\delta 3.64$ for $\mathbf{R} \boldsymbol{\beta})$ and H-6b ( $\delta 4.01$ for $\mathbf{R} \boldsymbol{\alpha}$ and $\delta 3.93$ for $\mathbf{R} \boldsymbol{\beta})$ resonances. ${ }^{8}$ Taking into account the ROESY inter-residual cross-peak between D H-1 and B H-4 (not shown), the set of H-3 and H-4 signals of residue $\mathbf{B}$ at $\delta 4.01$ and 3.66, respectively, indicated a $-(1 \rightarrow 4)-\alpha-D-G l c p-(1 \rightarrow 6)-$ unit for residue B. $^{8}$ The 


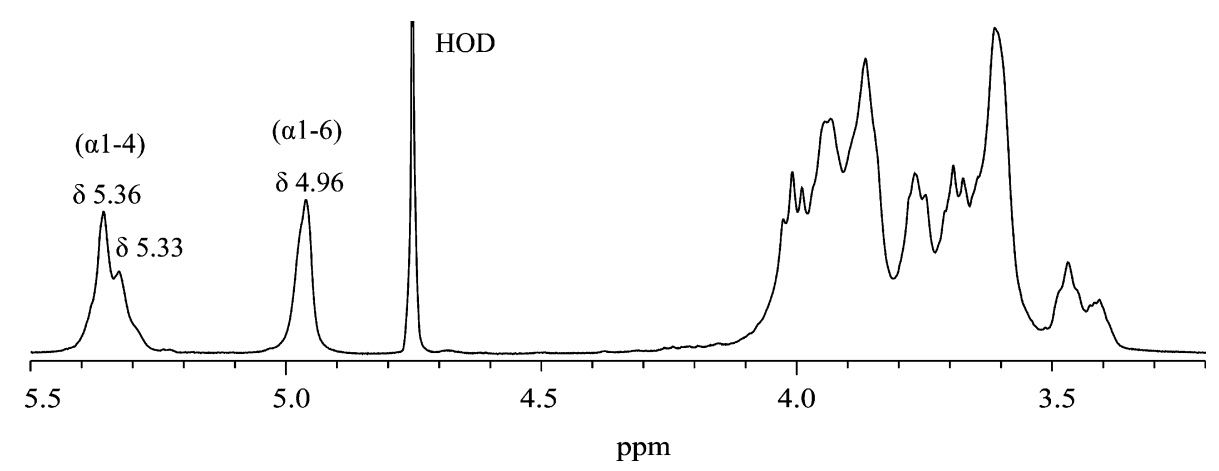

Figure 1. 500-MHz $1 \mathrm{D}{ }^{1} \mathrm{H}$ NMR spectrum of intact EPS35-5 recorded at $300 \mathrm{~K}$ in $\mathrm{D}_{2} \mathrm{O}$.
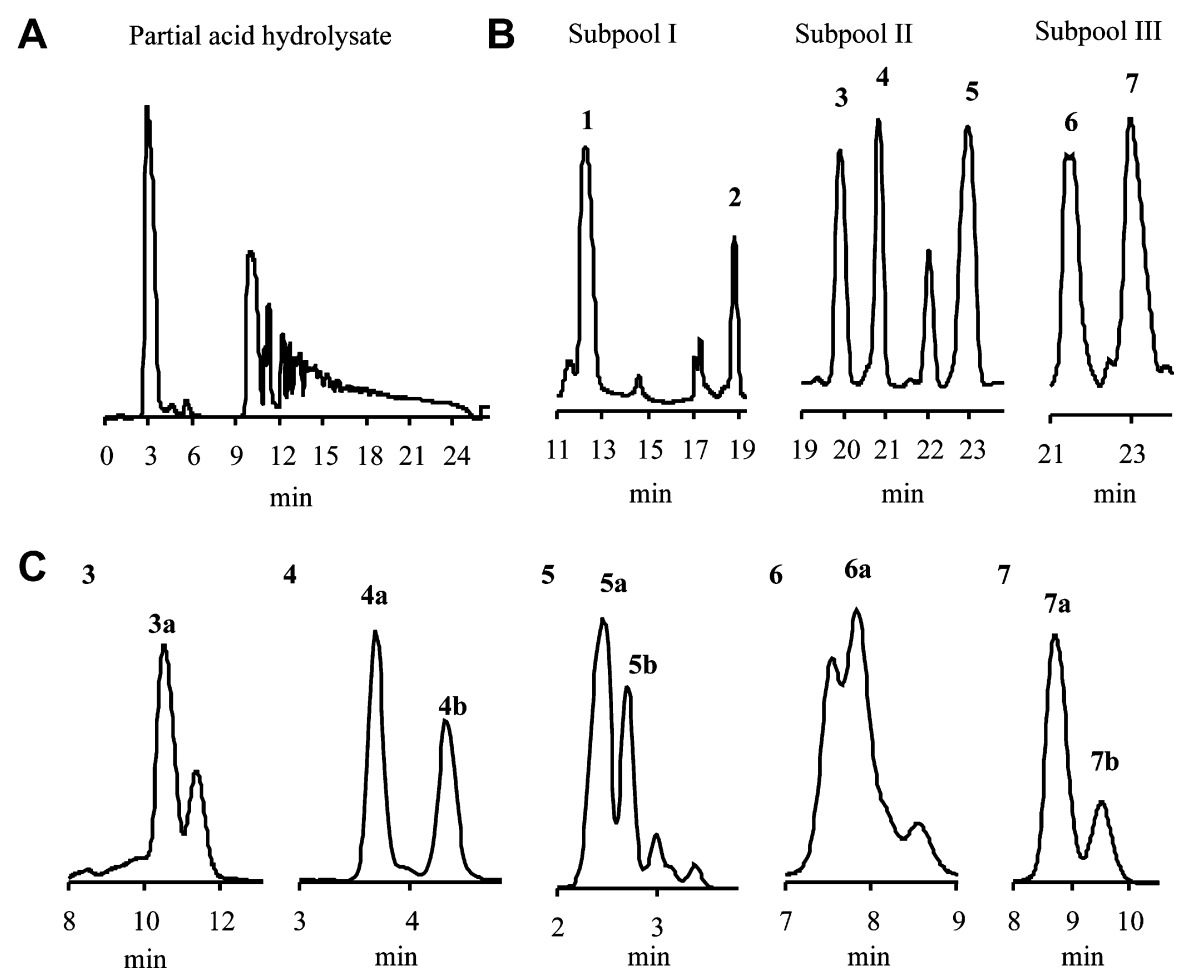

Figure 2. (A) HPAEC-PAD profile of EPS35-5 partial acid hydrolysate on CarboPac PA-100; (B) HPAEC-PAD profiles of Bio-Gel P-4 subpools I, II and III on CarboPac PA-1, using a linear gradient; and (C) HPAEC-PAD profiles of HPAEC fractions 3-7 on CarboPac PA-1, using isocratic conditions. For experimental details, see Section 4.

most notable signal on the D H-1 track of the TOCSY spectrum is the H-4 signal at $\delta 3.417$, which was identified as a marker for a terminal $\alpha$-D-Glcp- $(1 \rightarrow x)$ - unit ${ }^{8}$ the $\mathrm{H}-1$ value of $\mathbf{D}$ indicates the occurrence of an

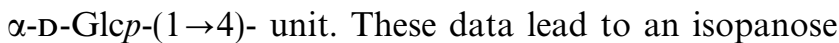
structure $\mathbf{D} 1 \rightarrow 4 \mathbf{B} 1 \rightarrow 6 \mathbf{R}$, that is, $\alpha$-D-Glc $p$ - $(1 \rightarrow 4)-\alpha-\mathrm{D}-$

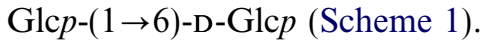

2.2.4. Fraction 4. The MALDI-TOF mass spectrum of fraction $\mathbf{4}$ showed an $[\mathrm{M}+\mathrm{Na}]^{+}$pseudomolecular ion at $m / z$ 527, corresponding with $\mathrm{Hex}_{3}$. Fraction 4 was further separated on CarboPac PA-1 (eluent: $100 \mathrm{mM}$ $\mathrm{NaOAc}$ in $100 \mathrm{mM} \mathrm{NaOH}$ ) (Fig. 2C), yielding major fraction $\mathbf{4 a}$ and minor fraction $\mathbf{4 b}$ (non-carbohydrate contaminant).

The 1D ${ }^{1} \mathrm{H}$ NMR spectrum of $\mathbf{4 a}$ (Fig. 4) showed four anomeric ${ }^{1} \mathrm{H}$ signals at $\delta$ 5.354/5.344 (D H-1, ${ }^{3} J_{1,2}$ $3.9 \mathrm{~Hz}), 5.222\left(\mathbf{R} \boldsymbol{\alpha} \mathrm{H}-1,{ }^{3} J_{1,2} 3.6 \mathrm{~Hz}\right), 4.985 / 4.976(\mathbf{E ~ H}-$ $\left.1,{ }^{3} J_{1,2} 3.8 \mathrm{~Hz}\right)$ and $4.660\left(\mathbf{R} \boldsymbol{\beta} \mathrm{H}-1,{ }^{3} J_{1,2} 8.1 \mathrm{~Hz}\right)$. Analysis of the $2 \mathrm{D}{ }^{1} \mathrm{H}-{ }^{1} \mathrm{H}$ TOCSY spectrum (Fig. $4 / 180 \mathrm{~ms}$ ) yielded all chemical shifts of the non-anomeric protons for residues $\mathbf{D}, \mathbf{E}$ and $\mathbf{R}$ (Table 1). In the absence of $(\alpha 1 \rightarrow 2)$ linkages, both the D H-4 ( $\delta 3.41)$ and E H-4 ( $\delta$ 3.43) values are indicative of a terminal $\alpha$-D-Glcp$(1 \rightarrow x)$ - residue. Taking into account the methylation analysis data of EPS35-5 (Section 2.1), D H-4 fits best 
A

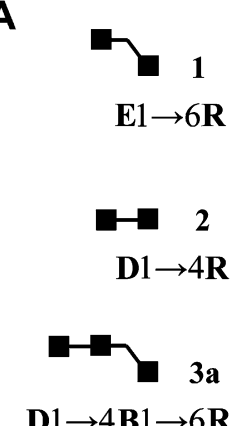

B
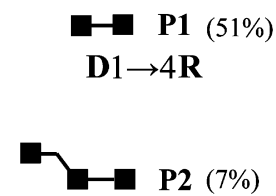

$\mathbf{E} 1 \rightarrow 6 \mathbf{A} 1 \rightarrow 4 \mathbf{R}$

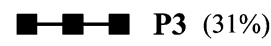

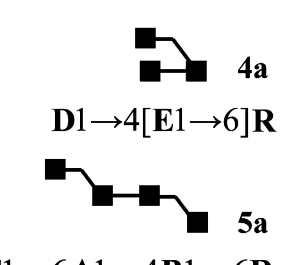

$\mathbf{E} 1 \rightarrow 6 \mathrm{~A} 1 \rightarrow 4 \mathrm{~B} 1 \rightarrow 6 \mathbf{R}$

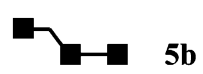

$\mathbf{E} 1 \rightarrow 6 \mathbf{A} 1 \rightarrow 4 \mathbf{R}$

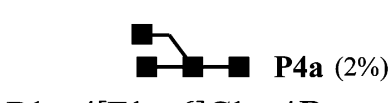

$\mathbf{D} 1 \rightarrow 4[\mathbf{E} 1 \rightarrow 6] \mathbf{C} 1 \rightarrow 4 \mathbf{R}$

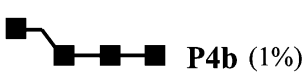

$\mathbf{E} 1 \rightarrow 6 \mathbf{A} 1 \rightarrow 4 \mathbf{F} 1 \rightarrow 4 \mathbf{R}$

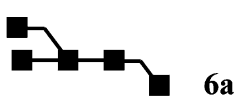

D $1 \rightarrow 4[\mathbf{E} 1 \rightarrow 6] \mathbf{C} 1 \rightarrow 4 \mathrm{~B} 1 \rightarrow 6 \mathbf{R}$

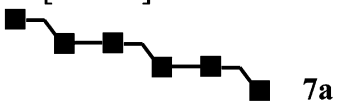

$\mathrm{E} 1 \rightarrow 6 \mathrm{~A} 1 \rightarrow 4 \mathrm{~B} 1 \rightarrow 6 \mathrm{~A} 1 \rightarrow 4 \mathrm{~B} 1 \rightarrow 6 \mathrm{R}$

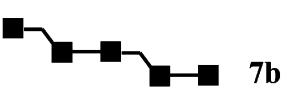

$\mathbf{E} 1 \rightarrow 6 \mathbf{A} 1 \rightarrow 4 \mathbf{B} 1 \rightarrow 6 \mathbf{A} 1 \rightarrow 4 \mathbf{R}$

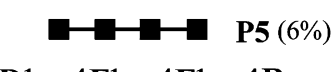

$\mathbf{D} 1 \rightarrow 4 \mathrm{~F} 1 \rightarrow 4 \mathrm{~F} 1 \rightarrow 4 \mathbf{R}$

$\mathrm{Hex}_{5} \mathbf{P 6}(2 \%)$

- : $\alpha-\mathrm{D}-\mathrm{Glc} p$

- : $1-4$ bond

ר : $1-6$ bond

Scheme 1. Structures of oligosaccharide fragments, obtained by (A) partial acid hydrolysis and (B) pullulanase M1 hydrolysis of EPS35-5. Quantities determined for the oligosaccharides obtained by pullulanase M1 hydrolysis are included between brackets.

with the occurrence of an $\alpha$-D-Glcp-( $1 \rightarrow 4)$ - unit and $\mathbf{E}$ H4 with that of an $\alpha$-D-Glc $p$ - $(1 \rightarrow 6)$ - unit. ${ }^{8}$ The chemical shifts of residue $\mathbf{R}$ H-3 ( $\mathbf{R} \boldsymbol{\alpha} \delta 3.99 ; \mathbf{R} \beta 3.78)$ are indicative of a 4-substitution, confirming the occurrence of a $\mathbf{D} 1 \rightarrow 4 \mathbf{R}$ structural element, ${ }^{8}$ which is further supported by the D H-1,R H-4 cross-peak in the 2D ROESY spectrum (Fig. 4). In the case of a 4-substitution, the H-5 signal is to be expected at $\delta \sim 3.94$ for $\mathbf{R} \boldsymbol{\alpha}$ and $\delta \sim 3.63$ for $\mathbf{R} \boldsymbol{\beta}$, however, in 4a the $\mathrm{H}-5$ signal is found at $\delta 4.11$ for $\mathbf{R} \boldsymbol{\alpha}$ and $\delta 3.89$ for $\mathbf{R} \boldsymbol{\beta}$, indicating the additional effect of a 6 -substitution. ${ }^{8}$ The occurrence of the $\mathbf{E} 1 \rightarrow 6 \mathbf{R}$ structural element is further supported by the H-6b chemical shifts of $\mathbf{R}$. These data lead to a $\mathbf{D} 1 \rightarrow 4[\mathbf{E} 1 \rightarrow 6] \mathbf{R}$ structure for compound $4 \mathbf{4}$, that is, $\alpha$-D-Glcp-( $1 \rightarrow 4)$-[ $\alpha-\mathrm{D}-\mathrm{Glc} p$ $(1 \rightarrow 6)-] \mathrm{D}-\mathrm{Glc} p$ (Scheme 1). The splitting of the anomeric signal of the $\alpha$-D-Glc $p$ - $(1 \rightarrow 6)$ - unit is also observed in isomaltose. ${ }^{8}$ The anomeric splitting observed across the $(\alpha 1 \rightarrow 4)$ bond in residue $\mathbf{D}$ had not been observed previously.

It should be noted that the 4,6-disubstitution of $\mathbf{R}$ yields a different set of $\mathbf{R} \boldsymbol{\alpha} \mathrm{H}-1$ and $\mathbf{R} \boldsymbol{\beta} \mathrm{H}-1$ chemical shift values. Also the $\mathbf{R} \boldsymbol{\alpha} \mathrm{H}-5$ resonance at $\delta 4.11$ can be considered as a new structural-reporter-group signal. These findings lead to a further fine-tuning of the structural-reporter-group concept, similar to the new structural reporters established for EPS180. ${ }^{9}$

2.2.5. Fraction 5. MALDI-TOF-MS analysis of fraction 5 revealed $[\mathrm{M}+\mathrm{Na}]^{+}$pseudomolecular ions at $\mathrm{m} / \mathrm{z}$ 527 and 689, corresponding with $\mathrm{Hex}_{3}$ and $\mathrm{Hex}_{4}$, respectively. Fraction 5 was further separated on CarboPac
PA-1 (eluent: $100 \mathrm{mM} \mathrm{NaOAc}$ in $100 \mathrm{mM} \mathrm{NaOH}$ ) (Fig. 2C), rendering a major fraction $\mathbf{5 a}$ and a minor fraction $\mathbf{5 b}$.

MALDI-TOF-MS analysis of $\mathbf{5 a}$ revealed an $[\mathrm{M}+\mathrm{Na}]^{+}$pseudomolecular ion at $\mathrm{m} / z$ 689, corresponding with $\mathrm{Hex}_{4}$. The ${ }^{1 D}{ }^{1} \mathrm{H}$ NMR spectrum of $\mathbf{5 a}$ (Fig. 3B) showed anomeric signals at $\delta 5.404(\mathbf{A ~ H}-1$, $\left.{ }^{3} J_{1,2} 3.8 \mathrm{~Hz}\right), 5.241\left(\mathbf{R} \boldsymbol{\alpha} \mathrm{H}-1,{ }^{3} J_{1,2} 3.6 \mathrm{~Hz}\right), 4.957(\mathbf{B} \mathrm{H}-$ 1 and $\left.\mathbf{E ~ H}-1,{ }^{3} J_{1,2} 3.4 \mathrm{~Hz}\right)$ and $4.669\left(\mathbf{R} \boldsymbol{\beta} \mathrm{H}-1,{ }^{3} J_{1,2}\right.$ $8.1 \mathrm{~Hz}$ ). Starting from the anomeric signals in the $2 \mathrm{D}$ ${ }^{1} \mathrm{H}-{ }^{1} \mathrm{H}$ TOCSY spectrum (not shown), all chemical shifts of the non-anomeric protons could be determined (Table 1). The chemical shift positions of $\mathrm{H}-1 \alpha$ and $\mathrm{H}-1 \beta$ of the reducing residue $\mathbf{R}$ at $\delta 5.241$ and 4.669 , respectively, are in agreement with the occurrence of a $-(1 \rightarrow 6)$-D-Glc $p$ unit. ${ }^{8,9}$ This is further reflected by the $\mathbf{R} \boldsymbol{\alpha}$ and $\mathbf{R} \boldsymbol{\beta} \mathrm{H}-5$ resonances at $\delta 4.00$ and 3.65, respectively (library data: $\delta 3.99-4.01$ and 3.63-3.65). ${ }^{8,9}$ The A $\mathrm{H}-1$ value at $5.404 \mathrm{ppm}$ is indicative of an (-) $\alpha$-D-

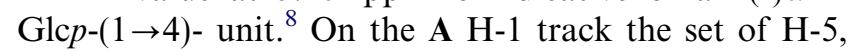
$\mathrm{H}-6 \mathrm{a}$ and $\mathrm{H}-6 \mathrm{~b}$ is observed at $\delta 3.90,3.72$ and 3.97, respectively, corresponding with a $-(1 \rightarrow 6)-\alpha-\mathrm{D}-\mathrm{Glc} p-$ $(1 \rightarrow 4)$ - unit (compare with panose) ${ }^{8}$ leading to the occurrence of a $\mathrm{X} 1 \rightarrow 6 \mathrm{~A} 1 \rightarrow 4 \mathrm{Y}$ element.

The overlapping anomeric signals of residues $\mathbf{B}$ and $\mathbf{E}$, indicative of $(-) \alpha$-D-Glc $p-(1 \rightarrow 6)$ - units, form a single track in the TOCSY spectrum. However, the difference between the two sets of H-2, H-3 and H-4 can clearly be observed in the built-up series of mixing times (data not shown). The chemical shifts of the set of $\mathbf{B}$ $\mathrm{H}-2, \mathrm{H}-3$ and H-4 at $\delta 3.60,3.99$ and 3.65, respectively, 

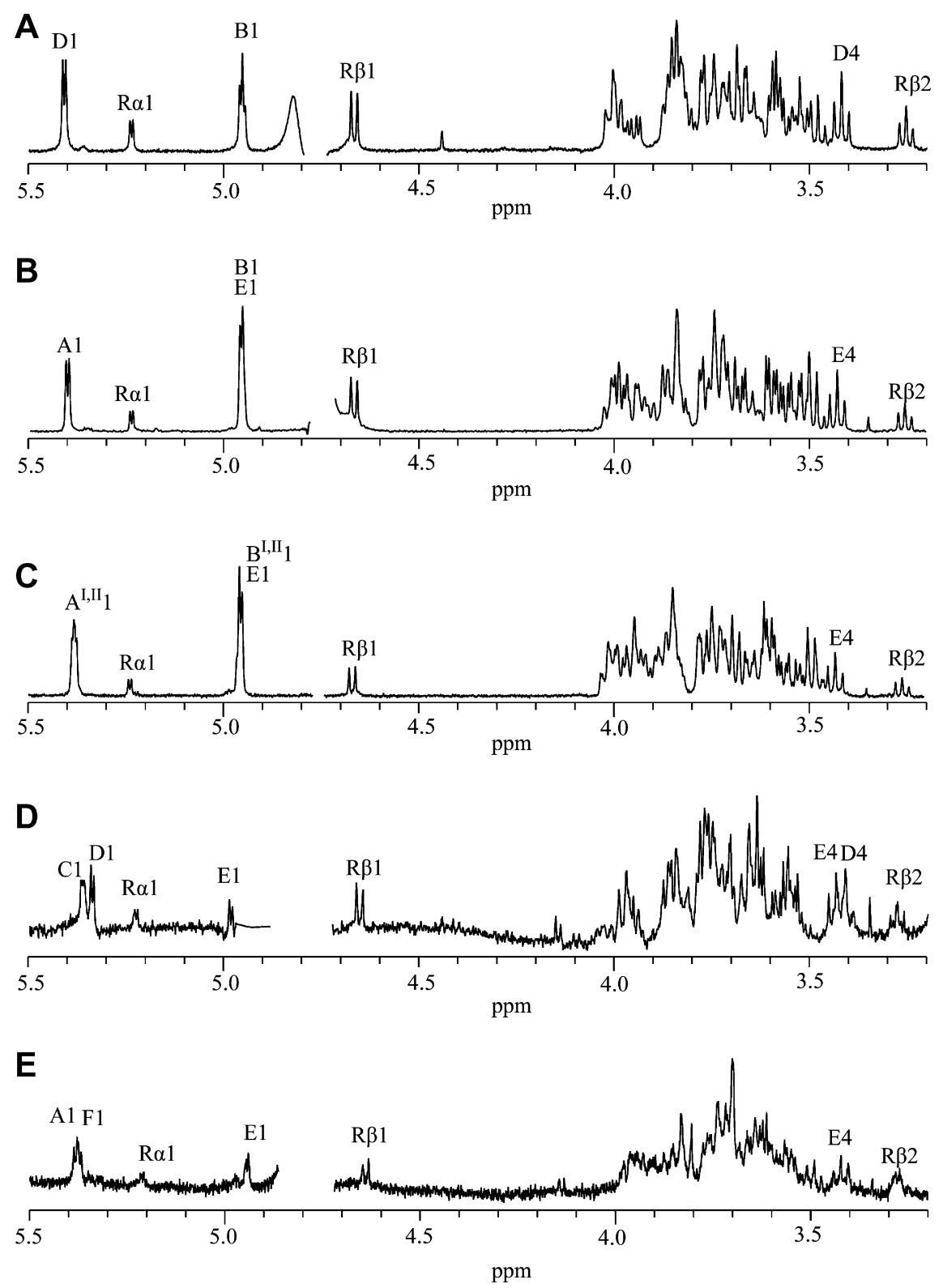

Figure 3. 500-MHz $1 \mathrm{D}^{1} \mathrm{H}$ NMR spectra of (A) fraction 3a, (B) fraction 5a, (C) fraction 7a, (D) compound $\mathbf{P 4 a}$ and (E) compound $\mathbf{P 4 b}$, recorded at $300 \mathrm{~K}$ in $\mathrm{D}_{2} \mathrm{O}$. Fractions 3a, 5a and 7a were obtained by partial acid hydrolysis of EPS35-5, and compounds P4a and P4b were obtained by pullulanase M1 hydrolysis of EPS35-5.

are indicative of the occurrence of a $-(1 \rightarrow 4)-\alpha-D-$

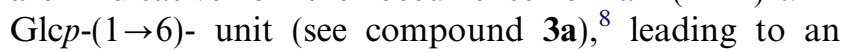
$\mathbf{X} 1 \rightarrow 6 \mathrm{~A} 1 \rightarrow 4 \mathrm{~B} 1 \rightarrow 6 \mathbf{Z}$ structure. The presence of $\mathbf{E ~ H}-4$ at $\delta 3.427(\mathrm{dd}, 1 \mathrm{H})$ reflects the occurrence of one termi-

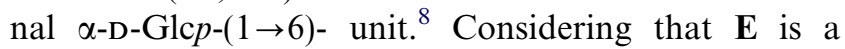
terminal residue and $\mathbf{R}$ the reducing residue leads unequivocally to the conclusion that compound $\mathbf{5 a}$ has the structure $\mathbf{E} 1 \rightarrow 6 \mathbf{A} 1 \rightarrow 4 \mathbf{B} 1 \rightarrow 6 \mathbf{R}$, that is, $\alpha$ -

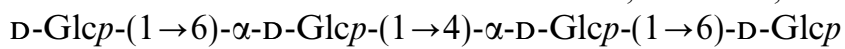
(Scheme 1).

The structure established for tetrasaccharide 5a was verified by $2 \mathrm{D}{ }^{1} \mathrm{H}-{ }^{1} \mathrm{H}$ ROESY measurements (not shown), showing inter-residual cross-peaks between A
H-1 and B H-4, B H-1 and R H-6a, and E H-1 and A $\mathrm{H}-6 \mathrm{a}$. It should be noted that the ${ }^{1} \mathrm{H}$ NMR data of $\mathbf{E} 1 \rightarrow 6 \mathbf{A} 1 \rightarrow 4$ perfectly fit those observed in the $\mathbf{E} 1 \rightarrow 6 \mathbf{A} 1 \rightarrow 4$ element of panose. ${ }^{8}$

The MALDI-TOF mass spectrum of $\mathbf{5 b}$ revealed an $[\mathrm{M}+\mathrm{Na}]^{+}$pseudomolecular ion at $\mathrm{m} / z$ 527, corresponding with $\mathrm{Hex}_{3}$. The $1 \mathrm{D}^{1} \mathrm{H}$ NMR spectrum matches that of panose, ${ }^{8}$ that is, $\alpha$-D-Glc $p-(1 \rightarrow 6)-\alpha-\mathrm{D}-\mathrm{Glc} p-(1 \rightarrow 4)-\mathrm{D}-$ Glcp (Scheme 1).

2.2.6. Fraction 6. MALDI-TOF-MS analysis of fraction 6 gave rise to a single $[\mathrm{M}+\mathrm{Na}]^{+}$pseudomolecular ion at $m / z$ 851, corresponding with $\mathrm{Hex}_{5}$. Fraction 6 
Table 1. ${ }^{1} \mathrm{H}$ chemical shifts of oligosaccharide fragments of EPS35-5 obtained by partial acid hydrolysis and of intact EPS35-5, measured at 300 K in $\mathrm{D}_{2} \mathrm{O}$

\begin{tabular}{|c|c|c|c|c|c|c|c|}
\hline & $3 \mathbf{a}$ & $4 a$ & $5 \mathbf{a}$ & $6 a$ & $7 \mathbf{a}$ & $7 \mathbf{b}$ & EPS35-5 \\
\hline $\mathrm{R} \alpha-1$ & 5.240 & 5.222 & 5.241 & 5.241 & 5.239 & 5.225 & - \\
\hline $\mathrm{R} \alpha-2$ & 3.55 & 3.59 & 3.54 & 3.55 & 3.55 & 3.58 & - \\
\hline $\mathrm{R} \alpha-3$ & 3.70 & 3.99 & 3.67 & 3.71 & 3.70 & 4.01 & - \\
\hline $\mathrm{R} \alpha-4$ & 3.52 & 3.67 & 3.50 & 3.50 & 3.50 & n.d. & - \\
\hline $\mathrm{R} \alpha-5$ & 4.00 & 4.113 & 4.00 & 4.00 & 4.00 & n.d. & - \\
\hline $\mathrm{R} \alpha-6 \mathrm{a}$ & 3.73 & 3.84 & 3.73 & 3.72 & 3.73 & n.d. & - \\
\hline $\mathrm{R} \alpha-6 \mathrm{~b}$ & 4.01 & 4.01 & 4.03 & 4.01 & 4.01 & n.d. & - \\
\hline $\mathrm{R} \beta-1$ & 4.669 & 4.660 & 4.669 & 4.670 & 4.669 & 4.649 & - \\
\hline $\mathrm{R} \beta-2$ & 3.253 & 3.285 & 3.253 & 3.257 & 3.255 & 3.271 & - \\
\hline$R \beta-3$ & 3.48 & 3.78 & 3.46 & 3.48 & 3.49 & 3.77 & - \\
\hline $\mathrm{R} \beta-4$ & 3.51 & 3.67 & 3.51 & 3.51 & 3.53 & 3.66 & - \\
\hline $\mathrm{R} \beta-5$ & 3.64 & 3.89 & 3.65 & 3.64 & 3.63 & 3.63 & - \\
\hline$R \beta-6 a$ & 3.75 & 3.78 & 3.80 & 3.76 & 3.77 & n.d. & - \\
\hline $\mathrm{R} \beta-6 \mathrm{~b}$ & 3.927 & 3.95 & 3.97 & 3.96 & 3.96 & n.d. & - \\
\hline A-2 & - & - & 3.60 & - & 3.60 & 3.60 & 3.60 \\
\hline A-3 & - & - & 3.68 & - & 3.70 & 3.70 & 3.70 \\
\hline A-4 & - & - & 3.496 & - & 3.492 & $3.497 / 92$ & 3.48 \\
\hline A-5 & - & - & 3.90 & - & 3.92 & 3.92 & n.d. \\
\hline A-6a & - & - & 3.72 & - & 3.75 & 3.74 & 3.74 \\
\hline$A-6 b$ & - & - & 3.97 & - & 3.97 & 3.96 & 3.94 \\
\hline B-1 & $4.958 / 50$ & - & 4.957 & $4.960 / 51$ & 4.955 & 4.954 & 4.96 \\
\hline B-2 & 3.60 & - & 3.60 & 3.61 & 3.60 & 3.61 & 3.61 \\
\hline B-3 & 4.01 & - & 3.99 & 4.01 & 4.01 & 4.00 & 4.01 \\
\hline B-4 & 3.66 & - & 3.65 & 3.65 & 3.66 & 3.65 & 3.65 \\
\hline B-5 & 3.85 & - & 3.85 & 3.85 & 3.85 & 3.85 & 3.85 \\
\hline B-6a & 3.86 & - & 3.85 & 3.86 & 3.86 & 3.87 & 3.89 \\
\hline B-6b & 3.80 & - & 3.82 & 3.83 & 3.82 & 3.84 & 3.85 \\
\hline C-1 & - & - & - & 5.361 & - & - & 5.33 \\
\hline $\mathrm{C}-2$ & - & - & - & 3.65 & - & - & 3.65 \\
\hline C-5 & - & - & - & 4.05 & - & - & 4.05 \\
\hline C-6a & - & - & - & n.d. & - & - & 3.91 \\
\hline$C-6 b$ & - & - & - & 3.97 & - & - & 3.97 \\
\hline D-1 & 5.412 & $5.354 / 44$ & - & 5.341 & - & - & 5.36 \\
\hline D-2 & 3.59 & 3.58 & - & 3.59 & - & - & 3.59 \\
\hline D-3 & 3.70 & 3.71 & - & 3.70 & - & - & 3.70 \\
\hline D-4 & 3.417 & 3.410 & - & 3.418 & - & - & 3.42 \\
\hline D-5 & 3.75 & 3.76 & - & 3.75 & - & - & 3.75 \\
\hline D-6a & 3.86 & 3.86 & - & 3.86 & - & - & n.d. \\
\hline D-6b & 3.78 & 3.77 & - & 3.77 & - & - & 3.77 \\
\hline E-1 & - & $4.985 / 76$ & 4.957 & 4.986 & 4.955 & 4.954 & 4.96 \\
\hline E-2 & - & 3.54 & 3.56 & 3.55 & 3.56 & 3.57 & 3.56 \\
\hline E-3 & - & 3.75 & 3.72 & 3.76 & 3.75 & 3.75 & 3.75 \\
\hline E-4 & - & 3.431 & 3.427 & 3.435 & 3.432 & 3.429 & 3.43 \\
\hline E-5 & - & 3.74 & 3.73 & 3.75 & 3.75 & 3.74 & 3.75 \\
\hline E-6a & - & 3.85 & 3.85 & n.d. & 3.85 & 3.85 & 3.85 \\
\hline E-6b & - & 3.76 & 3.74 & 3.77 & 3.77 & 3.75 & 3.75 \\
\hline $\mathrm{F}-1$ & - & - & - & - & - & - & 5.33 \\
\hline F-2 & - & - & - & - & - & - & 3.60 \\
\hline F-3 & - & - & - & - & - & - & 3.98 \\
\hline F-4 & - & - & - & - & - & - & 3.65 \\
\hline F-5 & - & - & - & - & - & - & 3.97 \\
\hline F-6a & - & - & - & - & - & - & n.d. \\
\hline F-6b & - & - & - & - & - & - & n.d. \\
\hline
\end{tabular}

Residue labels correspond to those used in Scheme 1. 

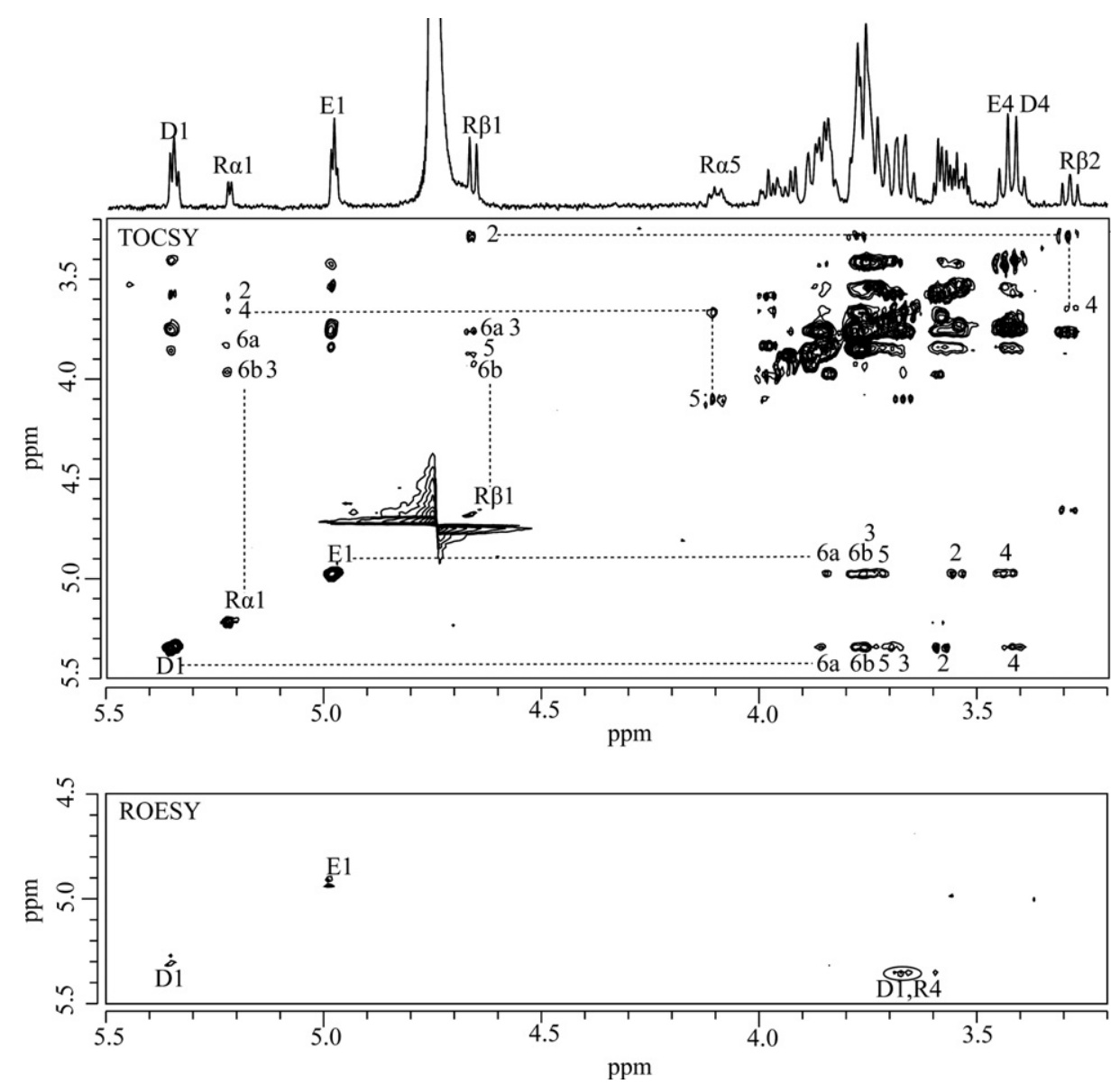

Figure 4. 500-MHz 1D ${ }^{1} \mathrm{H}$ NMR spectrum, 2D ${ }^{1} \mathrm{H}-{ }^{1} \mathrm{H}$ TOCSY spectrum (mixing time $180 \mathrm{~ms}$ ) and $2 \mathrm{D}{ }^{1} \mathrm{H}-{ }^{1} \mathrm{H}$ ROESY spectrum (mixing time $300 \mathrm{~ms}$ ) of fraction $4 \mathbf{a}$, recorded at $300 \mathrm{~K}$ in $\mathrm{D}_{2} \mathrm{O}$. Anomeric protons in the TOCSY spectrum (R $\alpha 1$, etc.) have been indicated on the diagonal; numbers in the horizontal and vertical tracks belong to the cross-peaks of the scalar-coupling network of the residues indicated. In the ROESY spectrum inter-residual couplings (D1,R4 means a cross-peak between D H-1 and R H-4, etc.) have been indicated with circles.

was further separated on CarboPac PA-1 under isocratic conditions (Fig. 2C), yielding one major fraction $\mathbf{6 a}$ $\left(\mathrm{Hex}_{5}\right)$.

The 1D ${ }^{1} \mathrm{H}$ NMR spectrum of $\mathbf{6 a}$ (Fig. 5) revealed six anomeric signals at $\delta 5.361\left(\mathbf{C ~ H}-1,{ }^{3} J_{1,2} 3.8 \mathrm{~Hz}\right), 5.341$ (D H-1, $\left.{ }^{3} J_{1,2} 3.6 \mathrm{~Hz}\right), 5.241\left(\mathbf{R} \boldsymbol{\alpha} \mathrm{H}-1,{ }^{3} J_{1,2} 3.8 \mathrm{~Hz}\right)$, 4.986 (E H-1, ${ }^{3} J_{1,2} 3.6 \mathrm{~Hz}$ ), 4.960/4.951 (B H-1, ${ }^{3} J_{1,2}$ $3.6 \mathrm{~Hz})$ and $4.670\left(\mathbf{R} \boldsymbol{\beta} \mathrm{H}-1,{ }^{3} J_{1,2} 7.9 \mathrm{~Hz}\right)$. The chemical shifts of the non-anomeric protons, as included in Table 1, were obtained from 2D TOCSY spectra with increasing mixing times (Fig. 5/180 ms). The chemical shift values of $\mathbf{R} \boldsymbol{\alpha}$ and $\mathbf{R} \boldsymbol{\beta} \mathrm{H}-1$ at $\delta 5.241$ and 4.670, respectively, correspond with the values established for the occurrence of a $-(1 \rightarrow 6)-\mathrm{D}-\mathrm{Glc} p$ unit. $^{8}$ The $\delta$ values of $\mathbf{R} \boldsymbol{\alpha}$ $\mathrm{H}-5$ at $4.00 \mathrm{ppm}$ and $\mathbf{R} \boldsymbol{\beta} \mathrm{H}-5$ at $3.64 \mathrm{ppm}$ confirm the 6-substitution of residue $\mathbf{R}^{8}{ }^{8}$ The $\mathrm{H}-1$ signal of residue $\mathbf{B}$, split into $\mathbf{B}_{\alpha}$ and $\mathbf{B}_{\beta}$ at $\delta 4.951$ and 4.960, respectively, corresponds with an (-) $\alpha-\mathrm{D}-\mathrm{Glc} p-(1 \rightarrow 6)$ - unit, influenced by the reducing residue anomeric configuration, suggesting a $\mathbf{B} 1 \rightarrow 6 \mathbf{R}$ element. The set of $\mathbf{B} \mathrm{H}-2, \mathrm{H}-3$ and $\mathrm{H}-4$ at $\delta 3.61,4.01$ and 3.65, respectively, revealed that $\mathbf{B}$ is a $-(1 \rightarrow 4)-\alpha-D-G l c p-(1 \rightarrow 6)-$ unit (see also com- pounds 3a and 5a). In a similar way as discussed for compound 4a, the D H-4 ( $\delta$ 3.418) and $\mathbf{E ~ H - 4 ~}(\delta$ $3.435)$ chemical shifts indicate the presence of a terminal $\alpha$-D-Glcp-D-( $1 \rightarrow 4)$ - and a terminal $\alpha$-D-Glcp-E-( $1 \rightarrow 6)$ unit, respectively. In fact, the $\mathbf{D}$ and $\mathbf{E ~ H - 1}$ signals at $\delta$ 5.341 and 4.986, respectively, match those of the D and $\mathbf{E}$ residues in $\mathbf{4 a}$, occurring in a $\mathbf{D} 1 \rightarrow 4[\mathbf{E} 1 \rightarrow 6] \mathbf{X}$ element. Taking into account that EPS35-5 only contains $(\alpha 1 \rightarrow 4)$ and $(\alpha 1 \rightarrow 6)$ linkages, the $\mathbf{C ~ H - 1}$ value $(\delta$ $5.361)$ has to be correlated with an $(\alpha 1 \rightarrow 4)$-linked residue. Moreover, the set of $\mathbf{C ~ H - 2 , H - 3}$ and $\mathrm{H}-4$ values indicates a $-(1 \rightarrow 4)-\alpha-\mathrm{D}-\mathrm{Glc} p-(1 \rightarrow 4)-$ unit. The H-5 signal, however, is found at $\delta 4.05$ (library maltotriose residue $\left.\mathbf{B}: \delta_{\mathrm{H}-5} 3.85\right),{ }^{8}$ being in favour of an additional 6-substitution (see compound 4a), and leading to the conclusion that residue $\mathbf{C}$ is a $-(1 \rightarrow 4,6)-\alpha-\mathrm{D}-\mathrm{Glc} p-$ $(1 \rightarrow 4)$ - unit. Taken together, these data lead to a $\mathbf{D} 1 \rightarrow 4[\mathbf{E} 1 \rightarrow 6] \mathbf{C} 1 \rightarrow 4 \mathbf{B} 1 \rightarrow 6 \mathbf{R}$ sequence for compound 6a, that is, $\alpha$-D-Glc $p-(1 \rightarrow 4)-[\alpha-\mathrm{D}-\mathrm{Glc} p-(1 \rightarrow 6)-] \alpha-\mathrm{D}-$

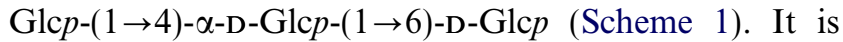
interesting to note that branching has a specific influence on the position of the $\mathrm{H}-1$ signal of the branched 

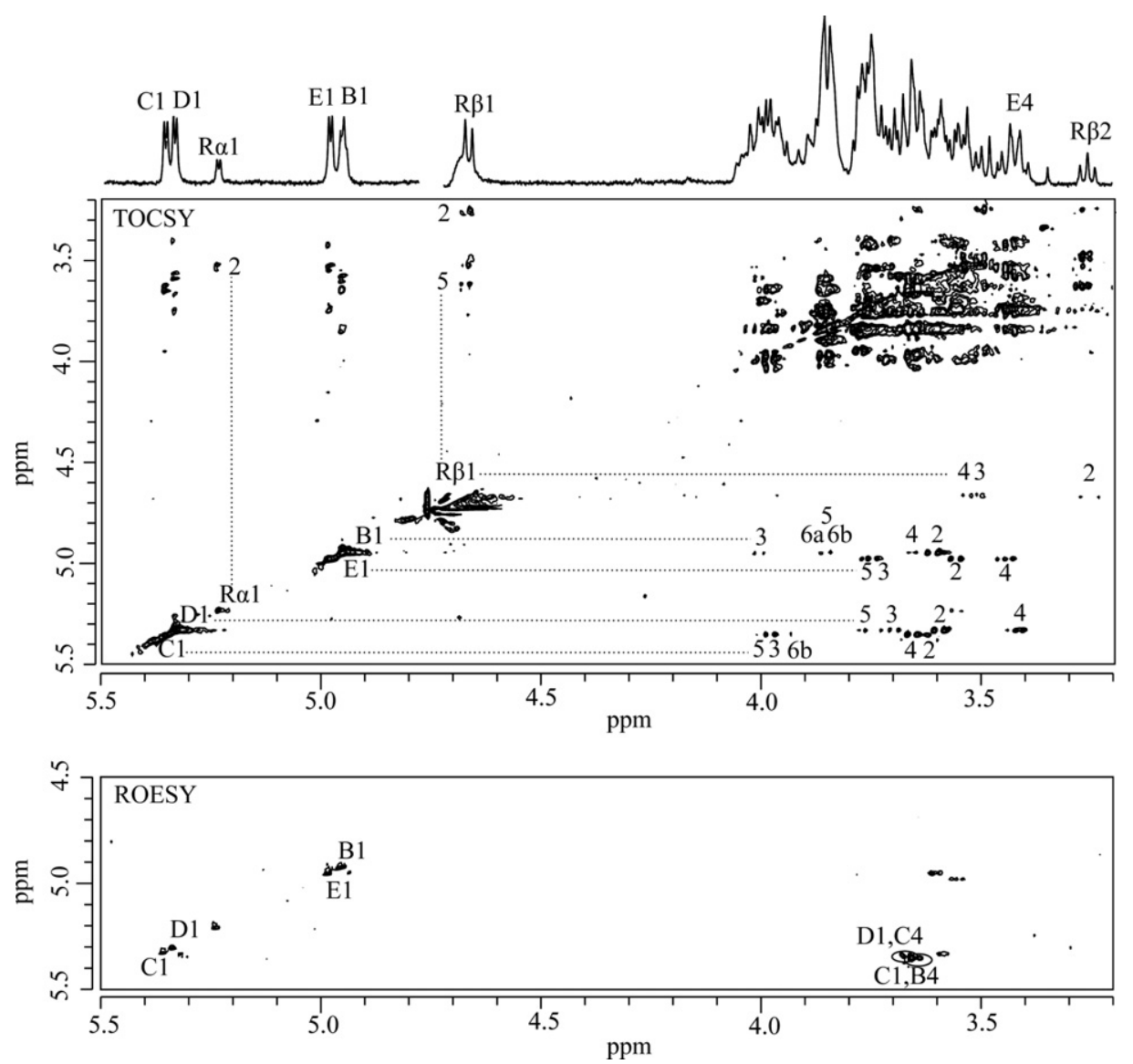

Figure 5. 500-MHz 1D ${ }^{1} \mathrm{H}$ NMR spectrum, $2 \mathrm{D}{ }^{1} \mathrm{H}-{ }^{1} \mathrm{H}$ TOCSY spectrum (mixing time $180 \mathrm{~ms}$ ) and $2 \mathrm{D}{ }^{1} \mathrm{H}-{ }^{1} \mathrm{H}$ ROESY spectrum (mixing time $300 \mathrm{~ms}$ ) of fraction $\mathbf{6 a}$, recorded at $300 \mathrm{~K}$ in $\mathrm{D}_{2} \mathrm{O}$. For an explanation of the coding systems, see Figure 4.

residue: $\delta 5.399$ for $-(1 \rightarrow 4)-\alpha-\mathrm{D}-\mathrm{Glc} p-(1 \rightarrow 4)$ - (maltotriose $)^{8}$ and $\delta 5.361$ for $-(1 \rightarrow 4,6)-\alpha-D-G l c p-(1 \rightarrow 4)-($ compound 6a). Remarkably, the downfield shift of H-5 when going from $-(1 \rightarrow 4)-\alpha$-D-Glcp- to $-(1 \rightarrow 4,6)-\alpha-\mathrm{D}-$ Glcp- in the case of residue $\mathbf{C}(\Delta \delta+0.20 \mathrm{ppm})$ is similar to that observed for residue $\mathbf{R} \boldsymbol{\alpha}$ in $\mathbf{4 a}(\Delta \delta+0.17 \mathrm{ppm})$.

The established structure of the pentasaccharide was verified by $2 \mathrm{D}{ }^{1} \mathrm{H}^{-1} \mathrm{H}$ ROESY measurements (Fig. 5), showing inter-residual cross-peaks between $\mathbf{C} \mathrm{H}-1$ and B H-4, and between $\mathbf{D} \mathrm{H}-1$ and $\mathbf{C} \mathrm{H}-4$. Inter-residual cross-peaks for $\mathbf{B} \mathrm{H}-1$ and $\mathbf{E} \mathrm{H}-1$ were not observed, due to low signal intensity.

2.2.7. Fraction 7. The MALDI-TOF mass spectrum of fraction 7 revealed $[\mathrm{M}+\mathrm{Na}]^{+}$pseudomolecular ions at $m / z 851$ and 1013, corresponding with $\mathrm{Hex}_{5}$ and $\mathrm{Hex}_{6}$, respectively. Fraction 7 was further separated on CarboPac PA-1 (eluent: $100 \mathrm{mM} \mathrm{NaOAc}$ in $100 \mathrm{mM}$ $\mathrm{NaOH}$ ) (Fig. 2C), yielding major fraction $7 \mathbf{a}\left(\mathrm{Hex}_{6}\right)$ and minor fraction $\mathbf{7 b}\left(\mathrm{Hex}_{5}\right)$.

The 1D ${ }^{1} \mathrm{H}$ NMR spectrum of 7a (Fig. 3C) showed anomeric signals at $\delta 5.387\left(\mathbf{A}^{\mathrm{I}} \mathrm{H}-1,{ }^{3} J_{1,2} 3.9 \mathrm{~Hz}\right)$, $5.380\left(\mathbf{A}^{\mathrm{II}} \mathrm{H}-1,{ }^{3} J_{1,2} 3.9 \mathrm{~Hz}\right), 5.239\left(\mathbf{R} \boldsymbol{\alpha} \mathrm{H}-1,{ }^{3} J_{1,2}\right.$ $3.6 \mathrm{~Hz}), 4.955\left(\mathbf{B}^{\mathrm{I}, \mathrm{II}} \mathrm{H}-1\right.$ and $\left.\mathbf{E} \mathrm{H}-1,{ }^{3} J_{1,2} 3.7 \mathrm{~Hz}\right)$ and
4.669 (Rß H-1, ${ }^{3} J_{1,2} 7.8 \mathrm{~Hz}$ ). Table 1 includes the chemical shifts of the various residual protons as determined by $2 \mathrm{D}^{1} \mathrm{H}_{-}{ }^{1} \mathrm{H}$ TOCSY analysis (not shown). In TOCSY experiments with different mixing times (data not shown) the built-up of the scalar coupling network could be followed. The set of $\mathrm{H}-1 \alpha$ and $\mathrm{H}-1 \beta$ chemical shifts of the reducing residue $\mathbf{R}$ corresponds with the

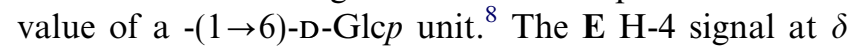
$3.432(\mathrm{dd}, 1 \mathrm{H})$ corresponds with a terminal $\alpha$-D-Glcp$(1 \rightarrow 6)$ - unit (compare with compounds $3 \mathbf{a}, \mathbf{4 a}, \mathbf{5 a}$ and 6a), thereby indicating a linear structure. Taking into account the methylation analysis data of EPS35-5, the A H-1 signals at $\delta 5.387$ and 5.380 reflect the occurrence

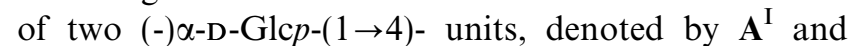
$\mathbf{A}^{\mathrm{II}}{ }^{8}$ The chemical shift patterns of $\mathbf{A}^{\mathrm{I}}$ and $\mathbf{A}^{\mathrm{II}}$ are the same and fit best with the values found for residue $\mathbf{A}$ in compound 5a, indicating two $-(1 \rightarrow 6)-\alpha-\mathrm{D}-$ Glcp$(1 \rightarrow 4)$ - units in compound $7 \mathbf{a}$ ( $\mathbf{A ~ H}-5$ at $\delta 3.92)$. The surface area of the $\mathbf{B}$ and $\mathbf{E}$ H-1 signals at $\delta 4.955$ matches $3 \mathrm{H}$, indicating the presence of three $(-) \alpha-\mathrm{D}-\mathrm{Glc} p-(1 \rightarrow 6)-$ units. In the TOCSY experiments with incremental mixing times (data not shown), two sets of chemical shifts could be observed. The set B H-2, H-3 and H-4 at $\delta$ $3.60,4.01$ and 3.66, respectively, matches the values of 
a -(1 $\rightarrow 4)-\alpha-D-G l c p-(1 \rightarrow 6)-$ unit (see compounds 3a, 5a and $\mathbf{6 a})$. Residue $\mathbf{E}$ showed the typical proton chemical shift pattern of a terminal $\alpha$-D-Glc $p-(1 \rightarrow 6)$ - unit (see above). Combination of the various data indicates that the hexasaccharide contains twice the $\mathbf{X} 1 \rightarrow 4 \mathbf{B} 1 \rightarrow 6 \mathbf{Y}$ sequence and twice the $\mathbf{X}^{\prime} 1 \rightarrow 6 \mathbf{A} 1 \rightarrow 4 \mathbf{Y}^{\prime}$ sequence. With residue $\mathbf{R}$ in an $\mathbf{X}^{\prime \prime} 1 \rightarrow 6 \mathbf{R}$ sequence and $\mathbf{E}$ as a terminal unit, these data lead to a $\mathbf{E} 1 \rightarrow 6 \mathbf{A}^{\mathrm{II}} 1 \rightarrow 4 \mathbf{B}^{\mathrm{II}} 1 \rightarrow 6 \mathbf{A}^{\mathrm{I}} 1 \rightarrow$ $4 \mathbf{B}^{\mathrm{I}} 1 \rightarrow 6 \mathbf{R}$ sequence for $7 \mathbf{a}$, that is, $\alpha-\mathrm{D}-\mathrm{Glc} p-(1 \rightarrow 6)$ $\alpha$-D-Glc $p$ - $(1 \rightarrow 4)-\alpha-\mathrm{D}-\mathrm{Glc} p-(1 \rightarrow 6)-\alpha-\mathrm{D}-\mathrm{Glc} p-(1 \rightarrow 4)-\alpha-\mathrm{D}-$ Glcp-(1 $\rightarrow 6)-\mathrm{D}-\mathrm{Glc} p$ (Scheme 1).

The structure of fraction $7 \mathbf{a}$ was verified by $2 \mathrm{D}{ }^{1} \mathrm{H}-{ }^{1} \mathrm{H}$ ROESY measurements (not shown), showing interresidual cross-peaks between $\mathbf{A} \mathrm{H}-1$ and $\mathbf{B} \mathrm{H}-4$, between B H-1 and A H-6a and R H-6a, and between E H-1 and A H-6a.

1D ${ }^{1} \mathrm{H}$ NMR analysis of fraction $7 \mathbf{b}$ (Fig. 6) revealed anomeric signals at $\delta 5.381\left(\mathbf{A}^{\mathrm{I}, \mathrm{II}} \mathrm{H}-1,{ }^{3} J_{1,2} 3.8 \mathrm{~Hz}\right)$, $5.225\left(\mathbf{R} \boldsymbol{\alpha ~ H}-1,{ }^{3} J_{1,2} 3.6 \mathrm{~Hz}\right), 4.954(\mathbf{B ~ H}-1$ and $\mathbf{E ~ H}-1$, $\left.{ }^{3} J_{1,2} 3.8 \mathrm{~Hz}\right)$ and $4.649\left(\mathbf{R} \boldsymbol{\beta} \mathrm{H}-1,{ }^{3} J_{1,2} 8.0 \mathrm{~Hz}\right)$. The chemical shift values as determined by $2 \mathrm{D}{ }^{1} \mathrm{H}-{ }^{1} \mathrm{H}$ TOCSY spectroscopy (Fig. 6/180 ms) are shown in Table 1. The set of anomeric signals of $\mathbf{R} \boldsymbol{\alpha}$ and $\mathbf{R} \boldsymbol{\beta}$ at $\delta 5.225$ and 4.649, respectively, corresponds with the occurrence of a $-(1 \rightarrow 4)-D-G l c p$ unit. ${ }^{8}$ Similar to compound $7 \mathbf{a}$, the two $\mathbf{A}$ residues of $\mathbf{7 b}$ that overlap on the $\mathbf{A}^{\mathbf{I}, \mathbf{I I}}$ TOCSY track develop exactly the same built-up chemical shift patterns in the TOCSY experiments with different mixing times (data not shown), demonstrating the presence of two $-(1 \rightarrow 6)-\alpha-D-G l c p-(1 \rightarrow 4)-$ units. Note also the similarity with residue $\mathbf{A}$ in compound 5a. The H-1 signal at $\delta 4.954(2 \mathrm{H})$ indicates the occurrence of two $(-) \alpha-D-G l c p-(1 \rightarrow 6)-$ units, that is, residues $\mathbf{B}$ and $\mathbf{E}$. In TOCSY experiments with incremental mixing times (data not shown) two distinctly different proton chemical shift patterns develop. The B H-3 resonance is observed at $\delta 4.00$, indicating a $-(1 \rightarrow 4)-\alpha-D-G l c p-(1 \rightarrow 6)$ unit. On guidance of the structural-reporter-group concept, the E H-4 signal at $\delta 3.429$ identified residue $\mathbf{E}$ as a terminal $\alpha$-D-Glc $p$ - $(1 \rightarrow 6)$ - unit. With twice the $\mathbf{X} 1 \rightarrow 6 \mathbf{A} 1 \rightarrow 4 \mathbf{Y}$ sequence and a 4 -substituted $\mathbf{R}$ unit, it can be concluded that compound $7 \mathbf{b}$ has a $\mathbf{E} 1 \rightarrow$ $6 \mathbf{A}^{\mathrm{II}} 1 \rightarrow 4 \mathrm{~B} 1 \rightarrow 6 \mathbf{A}^{\mathrm{I}} 1 \rightarrow 4 \mathbf{R}$ sequence, that is, $\alpha-\mathrm{D}-\mathrm{Glc} p$ $(1 \rightarrow 6)-\alpha-\mathrm{D}-\mathrm{Glc} p-(1 \rightarrow 4)-\alpha-\mathrm{D}-\mathrm{Glc} p-(1 \rightarrow 6)-\alpha-\mathrm{D}-\mathrm{Glc} p-(1 \rightarrow 4)-$ D-Glcp (Scheme 1).

The sequence established for pentasaccharide $7 \mathbf{b}$ was verified by $2 \mathrm{D}{ }^{1} \mathrm{H}-{ }^{1} \mathrm{H}$ ROESY measurements (Fig. 6), revealing inter-residual cross-peaks between $\mathbf{A}$ H-1 and
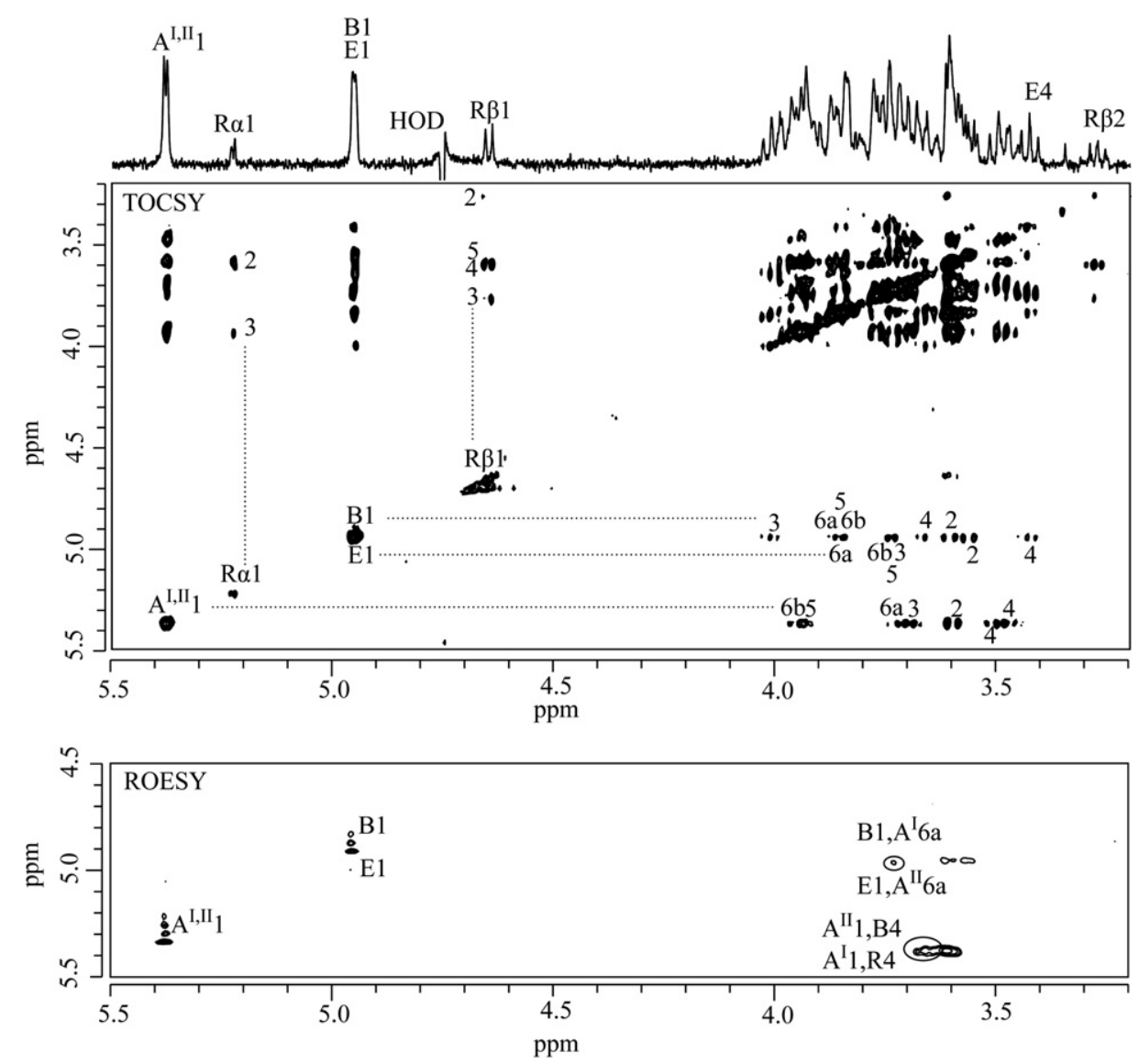

Figure 6. 500-MHz $1 \mathrm{D}{ }^{1} \mathrm{H}$ NMR spectrum, $2 \mathrm{D}{ }^{1} \mathrm{H}-{ }^{1} \mathrm{H}$ TOCSY spectrum (mixing time $180 \mathrm{~ms}$ ) and $2 \mathrm{D}{ }^{1} \mathrm{H}-{ }^{1} \mathrm{H}$ ROESY spectrum (mixing time $300 \mathrm{~ms}$ ) of fraction $\mathbf{7 b}$, recorded at $300 \mathrm{~K}$ in $\mathrm{D}_{2} \mathrm{O}$. For an explanation of the coding systems, see Figure 4. 
B H-4 and R $\boldsymbol{\beta} \mathrm{H}-4$, between $\mathbf{B} \mathrm{H}-1$ and $\mathbf{A}^{\mathrm{I}} \mathrm{H}-6 \mathrm{a}$, and between $\mathbf{E}$ H-1 and $\mathbf{A}^{\mathrm{II}} \mathrm{H}-6 \mathrm{a}$.

\subsection{D NMR spectroscopy of EPS35-5}

In order to unravel the $1 \mathrm{D}{ }^{1} \mathrm{H}$ NMR spectrum of EPS35-5 (Fig. 1), 2D TOCSY experiments with increasing mixing times of $10,30,60,120$ and $180 \mathrm{~ms}$, as well as data from the ${ }^{13} \mathrm{C}-{ }^{1} \mathrm{H}$ HSQC measurements of EPS35-5 were interpreted (Table 1) using the data collected from the oligosaccharides obtained by partial acid hydrolysis of EPS35-5 (Section 2.2).
In the $60 \mathrm{~ms}$ TOCSY spectrum (Fig. 7), the A/D H-1 track at $\delta 5.36$ (indicating $(\alpha 1 \rightarrow 4 \text { )-linked } \mathrm{D}-\mathrm{Glc} p)^{8}$ showed one chemical shift value for $\mathrm{H}-2$ at $\delta 3.60$ and one value for $\mathrm{H}-3$ at $\delta 3.70$, indicating that these residues are not 4-substituted (library data from maltotriose: $\delta_{\mathrm{H}-2} 3.63$ and $\left.\delta_{\mathrm{H}-3} 3.96\right) .{ }^{8}$ In the $120 \mathrm{~ms}$ TOCSY spectrum (Fig. 7) the A/D H-1 track revealed two different H-4 signals at $\delta 3.48$ (residue $\mathbf{A}$ ), indicating $-(1 \rightarrow 6)-\alpha-\mathrm{D}-\mathrm{Glc} p-(1 \rightarrow 4)$ - units (see residue $\mathbf{A}$ in $\mathbf{5 a}, \mathbf{7 a}$ and $\mathbf{7 b}$ ), and 3.42 (residue $\mathbf{D}$ ), indicating terminal $\alpha-\mathrm{D}-\mathrm{Glc} p-(1 \rightarrow 4)$ - units (see residue $\mathbf{D}$ in $\mathbf{3 a}, \mathbf{4 a}$ and $\mathbf{6 a})$.
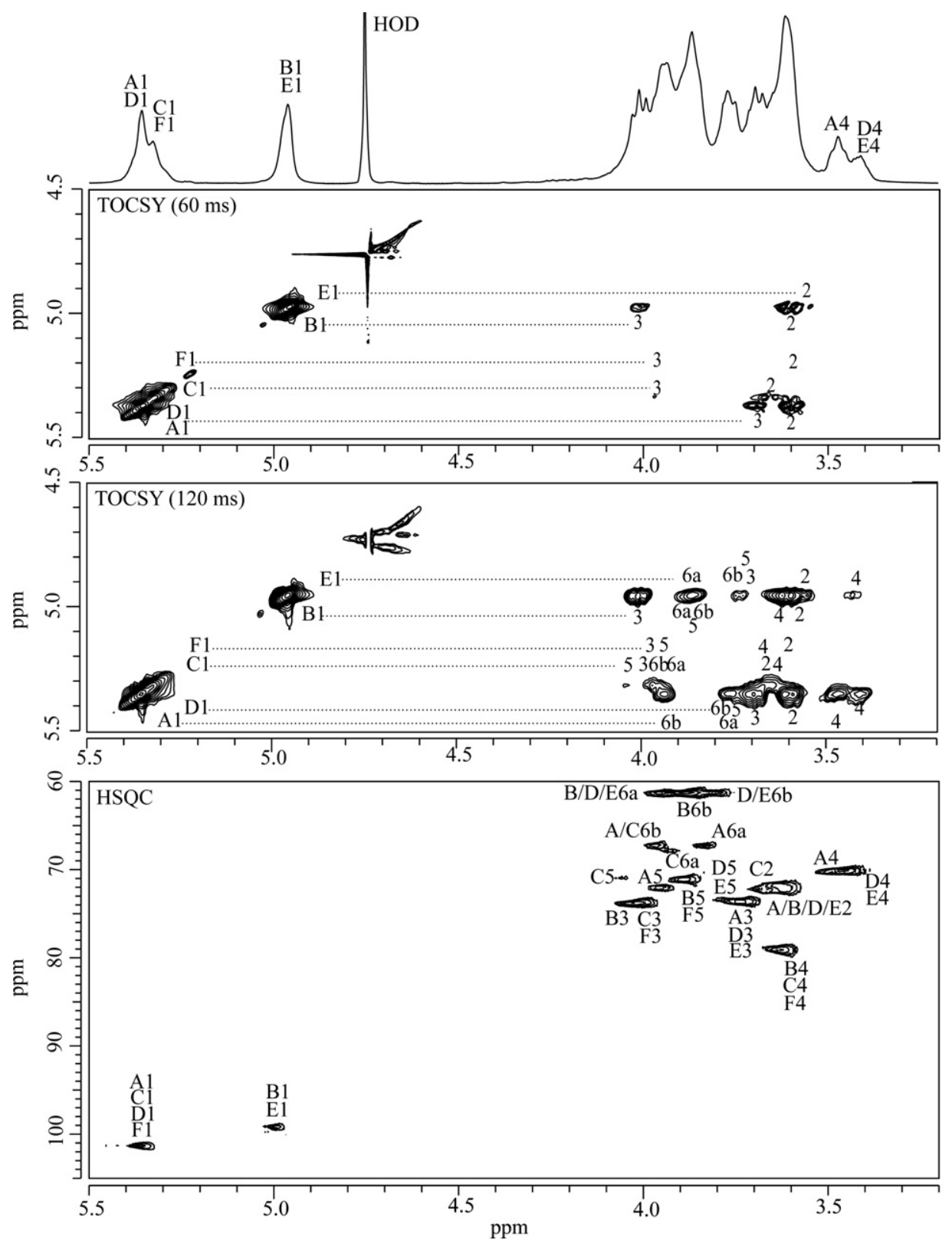

Figure 7. 500-MHz $1 \mathrm{D}^{1} \mathrm{H}$ NMR spectrum, $2 \mathrm{D}{ }^{1} \mathrm{H}-{ }^{1} \mathrm{H}$ TOCSY spectra (top, mixing time $60 \mathrm{~ms}$; bottom, $120 \mathrm{~ms}$ ) and $2 \mathrm{D}{ }^{13} \mathrm{C}-{ }^{1} \mathrm{H}$ HSQC spectrum of EPS35-5 recorded at $300 \mathrm{~K}$ in $\mathrm{D}_{2} \mathrm{O}$. Anomeric protons in the TOCSY spectrum (A1, etc.) have been indicated on the diagonal; numbers in the horizontal tracks belong to the cross-peaks of the scalar-coupling network of the residues indicated. In the ${ }^{13} \mathrm{C}-{ }^{1} \mathrm{H}$ HSQC spectrum A1 denotes the cross-peak between $\mathrm{H}-1$ and $\mathrm{C}-1$ of residue $\mathbf{A}$, etc. 
The C/F H-1 track in the $60 \mathrm{~ms}$ TOCSY spectrum at $\delta$ 5.33 (indicating $(\alpha 1 \rightarrow 4)$-linked $\mathrm{D}-\mathrm{Glc} p$ residues) showed two different $\mathbf{H}-2$ signals for residues $\mathbf{C}$ and $\mathbf{F}$ at $\delta 3.65$ (compare with residue $\mathbf{C}$ in $\mathbf{6 a}$ ) and 3.60, respectively, reflecting different substitution patterns (Scheme 1). The H-3 signal, however, is observed at $\delta 3.98$ for both residues, indicating the occurrence of $-(1 \rightarrow 4)-\alpha-\mathrm{D}-\mathrm{Glc} p$ $(1 \rightarrow 4)$ - units. The $\mathbf{C ~ H - 5 ~ r e s o n a n c e ~ a t ~} \delta 4.05$ fits with the occurrence of a $-(1 \rightarrow 4,6)-\alpha-\mathrm{D}-\mathrm{Glc} p-(1 \rightarrow 4)$ - unit (see residue $\mathbf{C}$ in $\mathbf{6 a}$ ).

On the B/E H-1 track in the $60 \mathrm{~ms}$ TOCSY spectrum at $\delta 4.96$ (indicating $(\alpha 1 \rightarrow 6)$-linked $\mathrm{D}-\mathrm{Glc} p$ residues) two different H-2 signals are observed, a strong signal at $\delta$ 3.61 (residue B) and a weak signal at $\delta 3.56$ (residue E). The set of B H-2 and H-3 at $\delta 3.61$ and 4.01 corresponds with the occurrence of a $-(1 \rightarrow 4)-\alpha-D-G l c p-$ $(1 \rightarrow 6)$ - unit (compare with residue $\mathbf{B}$ in $3 \mathbf{a}, \mathbf{5 a}, \mathbf{6 a}, 7 \mathbf{a}$ and $\mathbf{7 b}$ ). In the $120 \mathrm{~ms}$ TOCSY spectrum residue $\mathbf{E} \mathbf{H}-$ 4 is observed at $\delta 3.43$, in agreement with a terminal $\alpha$-D-Glcp-(1 $\rightarrow 6)$ - unit. Compare also the other chemical shift values with those found for residue $\mathbf{E}$ in compounds $\mathbf{4 a}, 5 \mathbf{a}, \mathbf{6 a}, 7 \mathbf{a}$ and $7 \mathbf{b}$ (Table 1). On the same track the set of $\mathbf{B} \mathrm{H}-4, \mathrm{H}-5, \mathrm{H}-6 \mathrm{a}$ and $\mathrm{H}-6 \mathrm{~b}$ supports the occurrence of a $-(1 \rightarrow 4)-\alpha-D-G l c p-(1 \rightarrow 6)-$ unit. The absence of a H-4 cross-peak at $\delta 3.50$ indicates that a $-(1 \rightarrow 6)-\alpha-D-G l c p-(1 \rightarrow 6)$ - element does not occur in EPS35-5. ${ }^{8,9}$ The fact that the $\mathrm{H}-6 \mathrm{a}$ and $\mathrm{H}-6 \mathrm{~b}$ values on the $(\alpha 1 \rightarrow 6)$ anomeric track exclude 6-substitution, further confirms the conclusion that only single $(\alpha 1 \rightarrow 6)$ bridges occur in EPS35-5.

The substitution patterns established from the TOCSY spectra were verified using ${ }^{13} \mathrm{C}-{ }^{1} \mathrm{H}$ HSQC spectroscopy (Fig. 7), yielding $\delta_{\mathrm{C}-4}$ values of $78.9 \mathrm{ppm}$ for residues $\mathbf{B}, \mathbf{C}$ and $\mathbf{F}$, reflecting the 4 -substitution of these residues. ${ }^{11}$ Residues $\mathbf{A}$ and $\mathbf{C}$ gave rise to $\delta_{\mathrm{C}-6}$ values of $67.1 \mathrm{ppm}$, reflecting the 6-substitution of these residues. ${ }^{11}$ For the residues $\mathbf{B}, \mathbf{D}$ and $\mathbf{E}$ the $\delta_{\mathrm{C}-6}$ value of $61.3 \mathrm{ppm}$ (F was not detected, due to minor occurrence) confirmed the absence of a 6-substitution.

\subsection{Enzymatic hydrolysis}

The occurrence of both $(\alpha 1 \rightarrow 4)$ and $(\alpha 1 \rightarrow 6)$ linkages in EPS35-5 may render the polysaccharide susceptible to hydrolysis by Klebsiella planticola pullulanase M1, which specifically cleaves the $(\alpha 1 \rightarrow 6)$ linkage in $(-) \alpha-D-$ Glc $p$ - $(1 \rightarrow 4)-\alpha$-D-Glcp-( $1 \rightarrow 6)-$ sequences. ${ }^{12}$ The substrate specificity of the commercially available enzyme was checked using a series of model compounds (data not shown).

A sample of EPS35-5 (20 mg) was incubated with pullulanase M1, and the initial progress of the hydrolysis was followed by analysing aliquots at 30, 60, 90 and $120 \mathrm{~min}$ by MALDI-TOF-MS and 1D ${ }^{1} \mathrm{H}$ NMR spectroscopy. As clear indications were obtained for the formation of oligosaccharide fragments (MALDI-TOF-
MS), accompanied by a decrease in the anomeric signal of $(-) \alpha-\mathrm{D}-\mathrm{Glc} p-(1 \rightarrow 6)-$ units $\left(\delta_{\mathrm{H}-1} 4.96 ; 1 \mathrm{D}{ }^{1} \mathrm{H}\right.$ NMR spectroscopy), the hydrolysis was continued for $96 \mathrm{~h}$. The resulting mixture was analysed by MALDI-TOF$\mathrm{MS}$, revealing $[\mathrm{M}+\mathrm{Na}]^{+}$pseudomolecular ions at $\mathrm{m} / \mathrm{z}$ 527, 689 and 851, corresponding with $\mathrm{Hex}_{3}, \mathrm{Hex}_{4}$ and $\mathrm{Hex}_{5}$, respectively. An aliquot of the mixture was analysed on CarboPac PA-100 (Fig. 8), using 0-300 mM $\mathrm{NaOAc}$ in $100 \mathrm{mM} \mathrm{NaOH}$ as eluent; for identification and quantification purposes a mixture of maltose, maltotriose, panose, maltotetraose, maltopentaose and maltohexaose standards was subjected to the same pullulanase hydrolysis and desalting procedure as the EPS35-5 sample, and also analysed on CarboPac PA-100, using 0-300 mM NaOAc in $100 \mathrm{mM} \mathrm{NaOH}$ as eluent. The bulk of the pullulanase M1 hydrolysate was separated on CarboPac PA-1, using the same elution conditions, yielding fractions P1 to P6.

2.4.1. Fraction P1. HPAEC and $1 \mathrm{D}{ }^{1} \mathrm{H}$ NMR analysis showed fraction $\mathbf{P 1}$ to contain maltose, ${ }^{8} \alpha-\mathrm{D}-\mathrm{Glc} p$ $(1 \rightarrow 4)-\mathrm{D}-\mathrm{Glc} p$. Using the response factor of maltose in the standard mixture, the relative amount of $\mathbf{P 1}$ in the hydrolysate was determined to be $51 \mathrm{~mol} \%$ (Scheme 1).

2.4.2. Fraction P2. MALDI-TOF-MS analysis of fraction $\mathbf{P 2}$ revealed an $[\mathrm{M}+\mathrm{Na}]^{+}$pseudomolecular ion at $m / z$ 527, corresponding with $\mathrm{Hex}_{3}$. The retention time of P2 on CarboPac PA-100 matched that of panose, whereas the 1D ${ }^{1} \mathrm{H}$ NMR spectrum of $\mathbf{P 2}$ corresponded with panose, ${ }^{8} \alpha$-D-Glc $p-(1 \rightarrow 6)-\alpha-\mathrm{D}-\mathrm{Glc} p-(1 \rightarrow 4)-\mathrm{D}-\mathrm{Glc} p$. Using the response factor of panose in the standard mixture, the relative amount of $\mathbf{P 2}$ was determined to be $7 \mathrm{~mol} \%$ (Scheme 1).

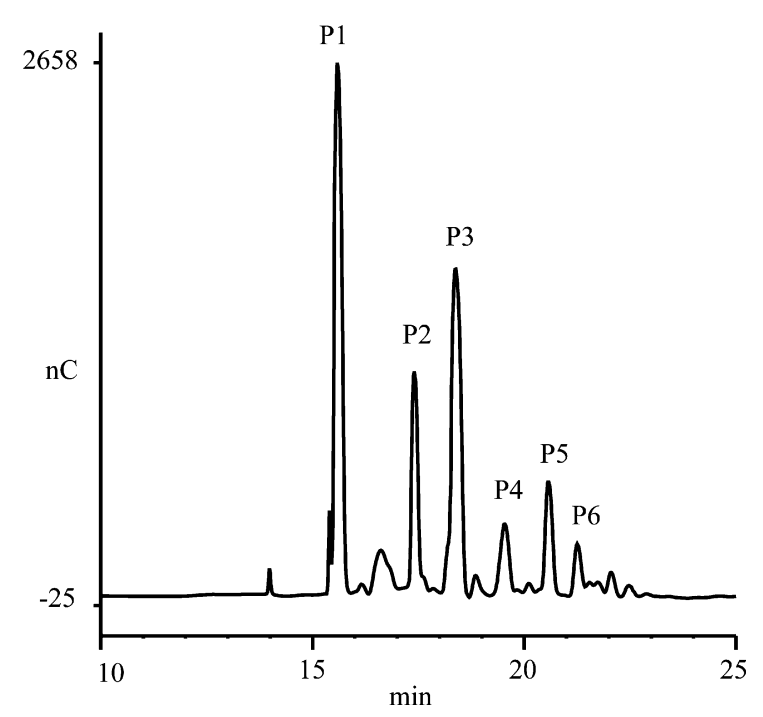

Figure 8. HPAEC-PAD profile of pullulanase M1 hydrolysate on CarboPac PA-100, using a linear gradient. 
2.4.3. Fraction P3. The MALDI-TOF mass spectrum of fraction $\mathbf{P 3}$ showed an $[\mathrm{M}+\mathrm{Na}]^{+}$pseudomolecular ion at $m / z 527$, corresponding with $\mathrm{Hex}_{3}$. The retention time of P3 on CarboPac PA-100 matched that of maltotriose, and the $1 \mathrm{D}^{1} \mathrm{H}$ NMR spectrum of $\mathbf{P 3}$ also corresponded with that of maltotriose, $\alpha$-D-Glcp$(1 \rightarrow 4)-\alpha-D-G l c p-(1 \rightarrow 4)-D-G l c p .{ }^{8}$ The amount of P3 was quantified, using the response factor of maltotriose, yielding $31 \mathrm{~mol} \%$ (Scheme 1).

2.4.4. Fraction P4. MALDI-TOF-MS analysis of fraction $\mathbf{P 4}$ revealed a single $[\mathrm{M}+\mathrm{Na}]^{+}$pseudomolecular ion at $\mathrm{m} / \mathrm{z}$ 689, corresponding with $\mathrm{Hex}_{4}$. Using the response factor of maltotetraose, the relative amount of $\mathbf{P 4}$ was estimated to be $3 \mathrm{~mol} \%$. The 1D ${ }^{1} \mathrm{H}$ NMR spectrum of $\mathbf{P 4}$ indicated the presence of a mixture of two components in a 2:1 ratio. Fraction $\mathbf{P 4}$ was further separated on CarboPac PA-1, using $100 \mathrm{mM} \mathrm{NaOAc}$ in $100 \mathrm{mM} \mathrm{NaOH}$, yielding a major fraction P4a $\left(\mathrm{Hex}_{4}\right)$ and a minor fraction $\mathbf{P} 4 \mathbf{b}\left(\mathrm{Hex}_{4}\right)$.

The 1D ${ }^{1} \mathrm{H}$ NMR spectrum of P4a (Fig. 3D) showed 5 anomeric signals at $\delta 5.363\left(\mathbf{C ~ H}-1,{ }^{3} J_{1,2} 3.2 \mathrm{~Hz}\right), 5.340$ (D H-1, $\left.{ }^{3} J_{1,2} 3.2 \mathrm{~Hz}\right), 5.226\left(\mathbf{R} \boldsymbol{\alpha} \mathrm{H}-1,{ }^{3} J_{1,2} 3.2 \mathrm{~Hz}\right)$, $4.985\left(\mathbf{E ~ H}-1,{ }^{3} J_{1,2} 3.2 \mathrm{~Hz}\right)$ and $4.655\left(\mathbf{R} \boldsymbol{\beta} \mathrm{H}-1,{ }^{3} J_{1,2}\right.$ $7.9 \mathrm{~Hz}$ ). The set of anomeric signals of $\mathbf{R} \boldsymbol{\alpha}$ and $\mathbf{R} \boldsymbol{\beta}$ corresponds with the occurrence of a reducing $-(1 \rightarrow 4)$ D-Glc $p$ unit. ${ }^{8}$ It is clear that one $(\alpha 1 \rightarrow 6)$-linked and two $(\alpha 1 \rightarrow 4)$-linked $\mathrm{D}-\mathrm{Glc} p$ residues are present in Hex $_{4}$. The H-1 signals of residues $\mathbf{C}, \mathbf{D}$ and $\mathbf{E}$ fit with the values observed in compound $\mathbf{6 a}$ for the D $1 \rightarrow 4[\mathbf{E} 1 \rightarrow 6] \mathbf{C}$ branch-point. Note the two overlapping $\mathrm{H}-4$ signals at $\delta 3.41$ and 3.43 , corresponding with the

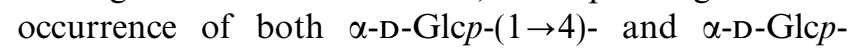
$(1 \rightarrow 6)$ - units. These data lead to the sequence $\mathbf{D} 1 \rightarrow$ $4[\mathbf{E} 1 \rightarrow 6] \mathbf{C} 1 \rightarrow 4 \mathbf{R}$ for $\mathbf{P 4 a}$, that is, $\alpha$-D-Glcp- $(1 \rightarrow 4)$ $[\alpha$-D-Glc $p-(1 \rightarrow 6)-] \alpha$-D-Glc $p$-( $1 \rightarrow 4)$-D-Glc $p$ (Scheme 1).

The 1D ${ }^{1} \mathrm{H}$ NMR spectrum of $\mathbf{P 4 b}$ (Fig. 3E) revealed two $(-) \alpha-\mathrm{D}-\mathrm{Glc} p-(1 \rightarrow 4)-$ units (residues $\mathbf{A}$ and $\mathbf{F}, \delta_{\mathrm{H}-1}$ $5.382,2 \mathrm{H})$ and one $(-) \alpha$-D-Glc $p-(1 \rightarrow 6)-$ unit (residue $\mathbf{E}$, $\left.\delta_{\mathrm{H}-1} 4.944,1 \mathrm{H}\right)$. Furthermore, only one $\mathrm{H}-4$ signal of a terminal residue at $\delta 3.43$ (residue $\mathbf{E}$ ) is observed, indicating a linear structure. The reducing residue $\mathbf{R} \mathrm{H}-1 \alpha$ and $\mathrm{H}-1 \beta$ resonances at $\delta 5.225$ and 4.650 , respectively, correspond with the occurrence of a reducing -( $1 \rightarrow 4)$-D-Glc $p$ unit. These data lead to an $\mathbf{E} 1 \rightarrow$ $6 \mathbf{A} 1 \rightarrow 4 \mathbf{F} 1 \rightarrow 4 \mathbf{R}$ sequence for the linear tetrasaccharide P4b, that is, $\alpha$-D-Glcp- $(1 \rightarrow 6)-\alpha-\mathrm{D}-\mathrm{Glc} p-(1 \rightarrow 4)-\alpha$-DGlc $p$ - $(1 \rightarrow 4)$-D-Glc $p$ (Scheme 1).

2.4.5. Fraction P5. The MALDI-TOF-MS spectrum of fraction $\mathbf{P 5}$ showed an $[\mathrm{M}+\mathrm{Na}]^{+}$pseudomolecular ion at $m / z$ 689, corresponding with $\mathrm{Hex}_{4}$. The retention time of P5 on CarboPac PA-100, as well as its 1D ${ }^{1} \mathrm{H}$ NMR spectrum, matched that of maltotetraose, $\alpha$ D-Glc $p-(1 \rightarrow 4)-\alpha$-D-Glc $p$ - $(1 \rightarrow 4)-\alpha$-D-Glc $p$ - $(1 \rightarrow 4)-\mathrm{D}-\mathrm{Glc} p$ (Scheme 1). Using the response factor of the maltotetra- ose standard, the relative amount of $\mathbf{P 5}$ was determined to be $6 \mathrm{~mol} \%$.

2.4.6. Fraction P6. Fraction $P 6$ was analysed by MALDI-TOF-MS, revealing an $[\mathrm{M}+\mathrm{Na}]^{+}$pseudomolecular ion at $m / z$ 851, corresponding with $\mathrm{Hex}_{5}$. The retention time of $\mathbf{P 6}$ on CarboPac PA-100 did not match that of maltopentaose, which eluted later than P6, indicating a structure with at least one $(\alpha 1 \rightarrow 6)$ linkage. Using the response factor of maltopentaose the relative abundance of P6 was estimated to be $2 \mathrm{~mol} \%$. Fraction P6 did not contain sufficient material for further analysis.

2.4.7. Evaluation of the pullulanase $M 1$ incubation. Based on MALDI-TOF-MS (not shown) and HPAEC-PAD (Fig. 8) analysis data, it can be concluded that the pullulanase M1 hydrolysis of EPS35-5 is complete. When taking into account the implicit $(\alpha 1 \rightarrow 6)$ linkage at the reducing side of the compounds presented in Scheme 1, the linkage distribution represented by these oligosaccharides in their abundances matches the linkage distribution determined by methylation analysis as well as 1D ${ }^{1} \mathrm{H}$ NMR data of full length EPS35-5, thereby confirming the completeness of the enzymatic hydrolysis. The various identified fragments describe all structural elements present in EPS35-5.

\section{Conclusions}

A composite model, that includes all identified structural features of the native EPS35-5 $\alpha$-D-glucan was formulated by combining ${ }^{1} \mathrm{H}$ NMR data of EPS35-5 with methylation analysis data (Section 2.1), as well as with structural information of oligosaccharides obtained by partial acid hydrolysis (Section 2.2) and pullulanase M1 hydrolysis (Section 2.4) of EPS35-5, and is depicted in Scheme 2. The methylation analysis data, combined with 1D ${ }^{1} \mathrm{H}$ NMR surface areas and pullulanase M1 fragment quantities dictate the boundaries for the distribution of the six types of building blocks in EPS35-5 (Table 2). All oligosaccharides obtained by partial acid hydrolysis and pullulanase M1 hydrolysis of EPS35-5 (Scheme 1) fit into the picture, reflecting the validity of the representation. It can be concluded that the $(1 \rightarrow 4,1 \rightarrow 6)-\alpha$-D-glucan of Lactobacillus reuteri strain 35-5 has a heterogeneous structure with no repeating units present. It is a built-up from maltose, maltotriose and maltotetraose elements with single $(\alpha 1 \rightarrow 6)$ bridges. The majority of the terminal residues are $\alpha$-D-Glcp$(1 \rightarrow 4)$ - units, however, a small amount of $\alpha$-D-Glcp$(1 \rightarrow 6)$ - units also occurs. The significant occurrence of compound P1 leads to a structure with large amounts of alternating $(\alpha 1 \rightarrow 4)$ and $(\alpha 1 \rightarrow 6)$ linkages. It should be noted that the advantage of constructing composite models is that $\alpha$-D-glucans isolated from different 


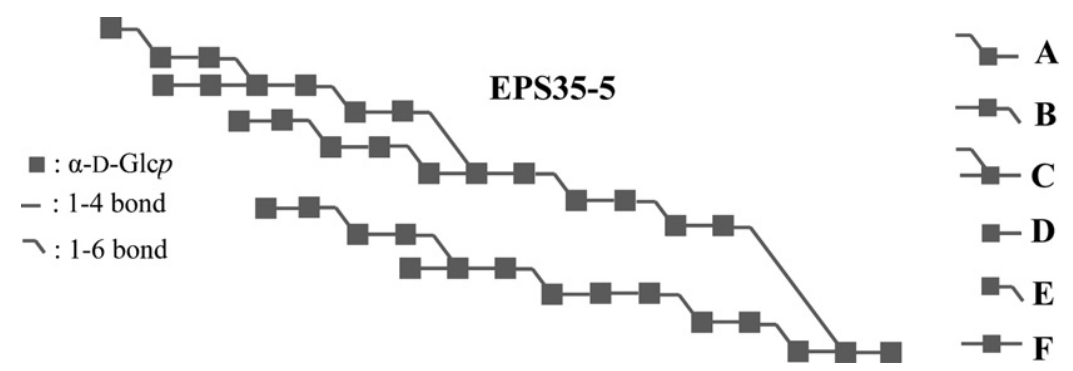

Scheme 2. Composite model of the native EPS35-5 $\alpha$-D-glucan. The composite takes into account all facts from the methylation analysis of EPS35-5 and the various ${ }^{1} \mathrm{H}$ NMR analyses of EPS35-5 and its established fragments. Residue labels correspond with those used in the text, tables and figures, and are presented on the right.

Table 2. Percentages of building blocks A-F present in EPS35-5

\begin{tabular}{lll}
\hline Building block & Code & Abundance $(\%)$ \\
\hline$-(1 \rightarrow 6)-\alpha-\mathrm{D}-$ Glc $p-(1 \rightarrow 4)-$ & A & 28 \\
$-(1 \rightarrow 4)-\alpha-\mathrm{D}-\mathrm{Glc} p-(1 \rightarrow 6)-$ & $\mathbf{B}$ & 38 \\
$-(1 \rightarrow 4,6)-\alpha-\mathrm{D}-\mathrm{Glc} p-(1 \rightarrow 4)-$ & $\mathbf{C}$ & 14 \\
$\alpha-\mathrm{D}-\mathrm{Glc} p-(1 \rightarrow 4)-$ & $\mathbf{D}$ & 10 \\
$\alpha-\mathrm{D}-\mathrm{Glc} p-(1 \rightarrow 6)-$ & $\mathbf{E}$ & 4 \\
$-(1 \rightarrow 4)-\alpha-\mathrm{D}-\mathrm{Glc} p-(1 \rightarrow 4)-$ & $\mathbf{F}$ & 6 \\
\hline
\end{tabular}

bacterial sources or prepared from sucrose by mutant glucansucrases can easily be compared.

\section{Materials and methods}

\subsection{Materials}

EPS35-5 was a gift from TNO Quality of Life, Zeist, The Netherlands. $\mathrm{D}_{2} \mathrm{O}$ (99.9 atom \%) was purchased from Cambridge isotope laboratories, Inc., Andover, MA. A suspension of pullulanase M1 (Klebsiella planticola) in $3.2 \mathrm{M}\left(\mathrm{NH}_{4}\right)_{2} \mathrm{SO}_{4}$ was purchased from Megazyme International Ireland Ltd, Bray, Ireland.

\subsection{Monosaccharide analysis}

A polysaccharide sample was subjected to methanolysis (1.0 M methanolic $\mathrm{HCl}, 24 \mathrm{~h}, 85^{\circ} \mathrm{C}$ ), followed by re-Nacetylation and trimethylsilylation (1:1:5 hexamethyldisilazane-trimethylchlorosilane-pyridine; $30 \mathrm{~min}$, room temperature). The mixture of trimethylsilylated methyl glycosides was analysed by GLC on an EC-1 column $(30 \mathrm{~m} \times 0.32 \mathrm{~mm}$, Alltech Associates Inc., Illinois, USA) using a Chrompack CP 9002 gas chromatograph (temperature gradient, $140-240{ }^{\circ} \mathrm{C}$ at $4{ }^{\circ} \mathrm{C} / \mathrm{min}$ ). The identification of the monosaccharide derivatives was confirmed by GLC-EI-MS. ${ }^{13}$

\subsection{Linkage analysis}

A polysaccharide sample was permethylated using $\mathrm{CH}_{3} \mathrm{I}$ and solid $\mathrm{NaOH}$ in DMSO, as described earlier. ${ }^{14}$ After hydrolysis with $2 \mathrm{MTFA}\left(2 \mathrm{~h}, 120^{\circ} \mathrm{C}\right)$, the partially methylated monosaccharides were reduced with $\mathrm{NaBD}_{4}$ ( $2 \mathrm{~h}$, room temperature). Conventional work-up, involving neutralisation with HOAc and removal of boric acid by co-evaporation with $\mathrm{MeOH}$, followed by acetylation with 1:1 $\mathrm{Ac}_{2} \mathrm{O}$-pyridine $\left(3 \mathrm{~h}, 120^{\circ} \mathrm{C}\right)$, yielded a mixture of partially methylated alditol acetates, which was analysed by GLC-EI-MS. ${ }^{13,15}$

\subsection{Partial acid hydrolysis}

In pilot experiments, 5-mg aliquots of EPS35-5 were hydrolysed for 30, 60, 90 and $120 \mathrm{~min}$ (0.5 M TFA, $\left.90^{\circ} \mathrm{C}\right)$. After concentration under reduced pressure, the residues were analysed by MALDI-TOF-MS and 1D ${ }^{1} \mathrm{H}$ NMR spectroscopy. Based on the initial results, EPS35-5 (500 mg) was hydrolysed in $25 \mathrm{~mL}$ of $0.5 \mathrm{M}$ TFA for $2 \mathrm{~h}$ at $90{ }^{\circ} \mathrm{C}$. The solution was concentrated under reduced pressure at a rotary evaporator, and the residue was separated on a Bio-Gel P-4 column $(400 \times 12 \mathrm{~mm}$, BioRad $)$, eluted with $25 \mathrm{mM} \mathrm{NH}_{4} \mathrm{HCO}_{3}$; $0.9-\mathrm{mL}$ fractions were collected at a flow rate of $13.5 \mathrm{~mL} / \mathrm{h}$. Fractions were tested for the presence of carbohydrate by a TLC spot-test with orcinol/ $\mathrm{H}_{2} \mathrm{SO}_{4}$ staining. Carbohydrate-containing fractions were analysed by MALDI-TOF-MS.

\subsection{Enzymatic hydrolysis}

An equimolar mixture of maltose, maltotriose, panose, maltotetraose, maltopentaose and maltohexaose $(50 \mathrm{mM}, 1 \mathrm{~mL})$ was dissolved in assay buffer $(50 \mathrm{mM}$ $\mathrm{NaOAc}$, pH 5.0 with $4 \mathrm{M} \mathrm{HOAc)}$, and subsequently $5 \mu \mathrm{L}$ pullulanase $\mathrm{M} 1$ suspension was added. A sample of $20 \mathrm{mg}$ EPS35-5 was dissolved in $2 \mathrm{~mL}$ assay buffer (see above), and $30 \mu \mathrm{L}$ pullulanase M1 suspension was added. Hydrolysis of samples was carried out for $96 \mathrm{~h}$ at $37^{\circ} \mathrm{C}$. From each sample aliquots were taken at $t=30,60,90$ and $120 \mathrm{~min}$, and subsequently boiled for 2 min to terminate enzymatic hydrolysis. Each sample was desalted on CarboGraph SPE columns (150 mg graphitised carbon, Alltech) using 1:3 acetonitrile- $\mathrm{H}_{2} \mathrm{O}$ as eluent, lyophilised, and subsequently analysed by 
HPAEC-PAD, MALDI-TOF-MS and 1D ${ }^{1} \mathrm{H}$ NMR spectroscopy. The bulk of the EPS35-5 sample was finally desalted, lyophilised and re-dissolved in $300 \mu \mathrm{L}$ $\mathrm{H}_{2} \mathrm{O}$. Pullulanase hydrolysis fragments were separated by HPAEC and analysed by MALDI-TOF-MS and 1D ${ }^{1} \mathrm{H}$ NMR spectroscopy.

\subsection{HPAEC-PAD}

High-pH anion-exchange chromatography was performed on a Dionex DX500 workstation, equipped with an ED40 pulsed amperometric detection (PAD) system. A triple-pulse amperometric waveform $\left(E_{1} 0.1 \mathrm{~V}, E_{2}\right.$ $0.7 \mathrm{~V}, E_{3}-0.1 \mathrm{~V}$ ) was used for detection with the gold electrode. ${ }^{16}$ Analytical separations were performed on a CarboPac PA-100 column $(250 \times 4 \mathrm{~mm}$, Dionex $)$, using a linear gradient of $0-300 \mathrm{mM} \mathrm{NaOAc}$ in $100 \mathrm{mM} \mathrm{NaOH}(1 \mathrm{~mL} / \mathrm{min})$. Samples were fractionated on a CarboPac PA-1 column $(250 \times 9 \mathrm{~mm}$, Dionex $)$, using a linear gradient of $0-300 \mathrm{mM} \mathrm{NaOAc}$ in $100 \mathrm{mM} \mathrm{NaOH}(4 \mathrm{~mL} / \mathrm{min})$ or isocratic conditions of $100 \mathrm{mM} \mathrm{NaOAc}$ in $100 \mathrm{mM} \mathrm{NaOH}(4 \mathrm{~mL} / \mathrm{min})$. Collected fractions were immediately neutralised with $4 \mathrm{M}$ HOAc, desalted on CarboGraph SPE columns (150 mg graphitised carbon, Alltech) using 1:3 acetonitrile- $\mathrm{H}_{2} \mathrm{O}$ as eluent and lyophilised.

\subsection{Mass spectrometry}

GLC-EI-MS was performed on a Fisons Instruments GC 8060/MD 800 system (Interscience BV; Breda, The Netherlands) equipped with an AT-1 column ( $30 \mathrm{~m} \times 0.25 \mathrm{~mm}$, Alltech), using a temperature gradient of $140-240{ }^{\circ} \mathrm{C}$ at $4^{\circ} \mathrm{C} / \mathrm{min} .{ }^{13}$

Matrix-assisted laser desorption ionisation timeof-flight mass spectrometry (MALDI-TOF-MS) was carried out on a Voyager-DE Pro (Applied Biosystems; Nieuwerkerk aan de IJssel, The Netherlands) instrument in the reflector mode at an accelerating voltage of $24 \mathrm{kV}$, using an extraction delay of $90 \mathrm{~ns}$, in a resolution of 5000-9000 FWMH. Samples $(1 \mu \mathrm{L})$ were mixed in a $1: 1$ ratio with a mixture of $7.5 \mathrm{mg} / \mathrm{mL} \mathrm{2,5-dihydroxy-}$ benzoic acid (DHB) in 1:1 acetonitrile- $\mathrm{H}_{2} \mathrm{O}$, and spectra were recorded in the positive-ion mode.

\subsection{NMR spectroscopy}

${ }^{1} \mathrm{H}$ NMR spectra, including ${ }^{1} \mathrm{H}-{ }^{1} \mathrm{H}$ and ${ }^{13} \mathrm{C}-{ }^{1} \mathrm{H}$ correlation spectra, were recorded on a Bruker DRX500 spectrometer (Bijvoet Center, Department of NMR spectroscopy, Utrecht University) at a probe temperature of $300 \mathrm{~K}$. Samples were exchanged once with 99.9 atom $\% \mathrm{D}_{2} \mathrm{O}$, lyophilised and dissolved in $650 \mu \mathrm{L} \mathrm{D} \mathrm{D}_{2} \mathrm{O}$. ${ }^{1} \mathrm{H}$ chemical shifts $(\delta)$ are expressed in ppm by reference to internal acetone $(\delta 2.225)$, and ${ }^{13} \mathrm{C}$ chemical shifts $(\delta)$ are expressed in ppm by reference to the methyl-carbon of internal acetone $(\delta 31.08) .1 \mathrm{D}{ }^{1} \mathrm{H}$ NMR spectra were recorded with a spectral width of $5000 \mathrm{~Hz}$ in $16 \mathrm{k}$ complex data sets and zero filled to $32 \mathrm{k}$. A WEFT pulse sequence was applied to suppress the HOD signal. ${ }^{17}$ When necessary, a fifth order polynomial baseline correction was applied. 2D TOCSY spectra were recorded using MLEV17 mixing sequences with spin-lock times of 10 , $30,60,120$ and $180 \mathrm{~ms}$. The spin-lock field strength corresponded to a $90^{\circ}$ pulse width of about $28 \mu$ s at $13 \mathrm{~dB}$. The spectral width in 2D TOCSY experiments was $4006 \mathrm{~Hz}$ at $500 \mathrm{MHz}$ in each dimension. 400-1024 spectra of $2 \mathrm{k}$ data points with 8-32 scans per $t_{1}$ increment were recorded. 2D rotating-frame nuclear Overhauser enhancement spectra (ROESY) were recorded with $300 \mathrm{~ms}$ mixing time. The spectral width was $4006 \mathrm{~Hz}$ at $500 \mathrm{MHz}$ in each dimension. Suppression of the HOD signal was performed by $1 \mathrm{~s}$ pre-saturation during the relaxation delay. Between 400 and 1024 data sets of $2 \mathrm{k}$ data points were recorded with $8-16$ scans per $t_{1}$ increment. $2 \mathrm{D}{ }^{13} \mathrm{C}-{ }^{1} \mathrm{H}$ HSQC spectroscopy was carried out at a ${ }^{1} \mathrm{H}$ frequency of $500.0821 \mathrm{MHz}$ and a ${ }^{13} \mathrm{C}$ frequency of $125.7552 \mathrm{MHz}$. Spectra were recorded with a spectral width of $4006 \mathrm{~Hz}$ for $t_{2}$ and $10 \mathrm{kHz}$ for $t_{1}$. The HOD signal was pre-saturated for $1 \mathrm{~s}$, and ${ }^{12} \mathrm{C}$-bound protons were suppressed using a TANGO pulse sequence. During acquisition of the ${ }^{1} \mathrm{H}$ FID, a ${ }^{13} \mathrm{C}$ decoupling pulse was applied. 128-256 experiments of $2 \mathrm{k}$ data points were recorded with 128 scans per $t_{1}$ increment. 2D NMR spectroscopic data were analysed by applying a sinus multiplication window and zero filling to spectra of $4 \mathrm{k}$ by $1 \mathrm{k}$ dimensions. In the case of ${ }^{13} \mathrm{C}-{ }^{1} \mathrm{H}$ HSQC data, the spectra were zero filled to $4 \mathrm{k}$ by 512 data points. A Fourier transform was applied, and where necessary, a fifth to fifteenth order polynomial baseline function was applied. All NMR data were processed using in-house developed software (J.A. van Kuik, Bijvoet Center, Department of Bio-Organic Chemistry, Utrecht University).

\section{Acknowledgement}

This work was financially supported by the Dutch Ministry of Economic Affairs (Senter Novem; Bioprimer project EETK01129).

\section{References}

1. Sandford, P. A.; Baird, J. In The Polysaccharides; Aspinall, G. O., Ed.; Academic Press: New York, 1983; Vol. 2, pp 411-490.

2. Costerton, J. W.; Cheng, K.-J.; Geesey, G. G.; Ladd, T. I.; Nickel, J. C.; Dasgupta, M.; Marrie, T. J. Annu. Rev. Microbiol. 1987, 41, 435-464.

3. Ceri, H.; McArthur, H. A. I.; Whitfield, C. Infect. Immun. 1986, 51, 1-5.

4. De Vuyst, L.; Degeest, B. FEMS Microbiol. Rev. 1999, 23, 153-177. 
5. Monchois, V.; Willemot, R.-M.; Monsan, P. FEMS Microbiol. Rev. 1999, 23, 131-151.

6. Funane, K.; Ishii, T.; Matsushita, M.; Hori, K.; Mizuno, K.; Takahara, H.; Kitamura, Y.; Kobayashi, M. Carbohydr. Res. 2001, 334, 19-25.

7. Argüello-Morales, M. A.; Remaud-Simeon, M.; Pizzut, S.; Sarçabal, P.; Willemon, R.-M.; Monsan, P. FEMS Microbiol. Lett. 2000, 182, 81-85.

8. Van Leeuwen, S. S.; Leeflang, B. R.; Gerwig, G. J.; Kamerling, J. P. Carbohydr. Res., in press, doi:10.1016/ j.carres.2008.01.043.

9. Van Leeuwen, S. S.; Kralj, S.; van Geel-Schutten, G. H.; Gerwig, G. J.; Dijkhuizen, L.; Kamerling, J. P. Carbohydr. Res., in press, doi:10.1016/j.carres.2008.01.042.

10. Kralj, S.; van Geel-Schutten, G. H.; Rahaoui, H.; Leer, R. J.; Faber, E. J.; van der Maarel, M. J. E. C.; Dijkhuizen, L. Appl. Environ. Microbiol. 2002, 68, 4283-4291.
11. Bock, K.; Thøgersen, H. Ann. Rep. NMR Spectrosc. 1982 , 13, 2-57.

12. Domań-Pytka, M.; Bardowski, J. Crit. Rev. Microbiol. 2004, 30, 107-121.

13. Kamerling, J. P.; Vliegenthart, J. F. G. In Mass Spectrometry; Lawson, A. M., Ed.; Clinical BiochemistryPrinciples, Methods, Applications; Walter de Gruyter: Berlin, 1989; Vol. 1, pp 176-263.

14. Ciucanu, I.; Kerek, F. Carbohydr. Res. 1984, 131, 209217.

15. Jansson, P.-E.; Kenne, L.; Liedgren, H.; Lindberg, B.; Lönngren, J. Chem. Commun. Univ. Stockholm 1976, 8, 174.

16. Lee, Y. C. Anal. Biochem. 1990, 189, 151-162.

17. Hård, K.; van Zadelhoff, G.; Moonen, P.; Kamerling, J. P.; Vliegenthart, J. F. G. Eur. J. Biochem. 1992, 209, 895915. 